\title{
Competitive coordination of the dual roles of the Hedgehog co-receptor in homophilic adhesion and signal reception
}

Shu Yang ${ }^{1,2 \&}$, Ya Zhang ${ }^{1,2 \&}$, Chuxuan Yang ${ }^{3 \&}$, Xuefeng Wu ${ }^{1,2}$, Sarah Maria El Oud ${ }^{3}$, Rongfang Chen ${ }^{1,2}$, Xudong Cai ${ }^{1,2}$, Xufeng S. Wu ${ }^{4}$, Ganhui Lan ${ }^{3,{ }^{*}}$, and Xiaoyan Zheng ${ }^{1,2,{ }^{*}}$

One-sentence summary: Apparently incompatible functions of lhog in homophilic adhesion and ligand binding cooperate in Hh transport and reception.

${ }^{1}$ Department of Anatomy and Cell Biology, George Washington University School of Medicine and Health Sciences, Washington, DC 20037, USA

${ }^{2} \mathrm{GW}$ Cancer Center, George Washington University School of Medicine and Health Sciences, Washington, DC 20052, USA

${ }^{3}$ Department of Physics, George Washington University, Washington, DC 20052, USA

${ }^{4}$ Laboratory of Cell Biology, National Heart, Lung, and Blood Institute, National Institutes of Health, Bethesda, MD 20892, USA.

${ }^{\&}$ These authors contributed equally to this work.

*To whom correspondence may be addressed: Xiaoyan Zheng, xzheng@gwu.edu, Tel: 202994-4228. SEH Suite 8840. 800 22nd St. NW. Washington, DC 20052; Ganhui Lan, glan@gwu.edu, Tel: 202-994-3864. SEH Suite 4680. 800 22nd St. NW. Washington, DC 20052. \#Lead Contact: Xiaoyan Zheng, xzheng@gwu.edu, Tel: 202-994-4228. SEH Suite 8840. 800 22nd St. NW. Washington, DC 20052 


\section{ABSTRACT}

Hedgehog $(\mathrm{Hh})$ signaling patterns embryonic tissues and contributes to homeostasis in adults. In Drosophila, Hh transport and signaling are thought to occur along a specialized class of actinrich filopodia, termed cytonemes. Here, we report that Interference hedgehog (Ihog) not only forms a Hh receptor complex with Patched to mediate intracellular signaling, but Ihog also engages in trans-homophilic binding leading to cytoneme stabilization in a manner independent of its role as the Hh receptor. Both functions of Ihog (trans-homophilic binding for cytoneme stabilization and Hh binding for ligand sensing) involve a region of the first fibronectin repeat of the extracellular domain. Thus, the Ihog-lhog interaction and the Hh-lhog interaction cannot occur simultaneously for a single Ihog molecule. By combining experimental data and mathematical modeling, we determined that $\mathrm{Hh}$-Ihog heterophilic interaction dominates and $\mathrm{Hh}$ can disrupt and displace Ihog molecules involved in trans-homophilic binding. Consequently, we proposed that the weaker lhog-Ihog trans interaction promotes and stabilizes direct membrane contacts along cytonemes and that, as the cytoneme encounters secreted Hh ligands, the ligands trigger release of Ihog from trans Ihog-Ihog complex enabling transport or internalization of the Hh ligand-Ihog-Patched -receptor complex. Thus, the seemingly incompatible functions of Ihog in homophilic adhesion and ligand binding cooperate to assist Hh transport and reception along the cytonemes. 


\section{INTRODUCTION}

Hedgehog $(\mathrm{Hh})$ signaling plays essential roles in patterning of multicellular embryos and maintaining adult organ homeostasis. Aberration in the precise temporal-spatial regulation and transduction of the Hh signaling pathway is involved in some birth defects (Muenke and Beachy 2000) and various proliferative disorders, such as the growth of malignant tumors (Varjosalo and Taipale 2008).

Hh protein precursor undergoes autoprocessing and lipid modification that generates the mature Hh ligand as an amino-terminal signaling peptide $(\mathrm{HhN})$ dually modified by palmitoyl and cholesteryl adducts (Mann and Beachy 2004). Intracellular signaling is triggered by binding of the dually lipidated $\mathrm{Hh}$ ligand to the receptor. The Drosophila $\mathrm{Hh}$ receptor regulates the component, Smoothened, and limits the range of signaling by sequestering $\mathrm{Hh}$ ligand. The Hh receptor is comprised of Patched $(\mathrm{Ptc})$ and a member of the Ihog family, which in Drosophila is one of the functionally interchangeable proteins encoded by interference Hedgehog (ihog) or brother of ihog (boi) (Lum et al. 2003; McLellan et al. 2006; Yao et al. 2006; Camp et al. 2010; Chou et al. 2010; Hartman et al. 2010; Yan et al. 2010; Zheng et al. 2010).

The Ihog family proteins are type I single-span transmembrane proteins with immunoglobulin (Ig) and fibronectin type III (FNIII) domains, resembling typical cell adhesion molecules in the Ig-CAM (Ig cell adhesion molecule) superfamily. Previous biochemical and structural studies showed that the first FNIII domain (Fn1) in the extracellular portion of Ihog is involved in binding to the Hh ligand (McLellan et al. 2006; Yao et al. 2006), whereas the second FNIII domain (Fn2) of Ihog interacts with Ptc. Both Fn1 and Fn2 domains are required for Hh signal reception through the formation of a high-affinity multimolecular complex of Ihog, Ptc, and Hh (Zheng et al. 2010). Ihog proteins not only play an essential role in Hh signal transduction but also mediate cell-cell interactions in a homophilic, calcium-independent manner (Zheng et al. 2010; Hsia et al. 2017; Wu et al. 2019). The region that mediates the trans Ihog-Ihog interaction overlaps with the region that mediates the interaction with $\mathrm{Hh}$ on the lhog Fn1 
domain and includes a region where the negatively charged glycan heparin binds (McLellan et al., 2006; Wu et al., 2019). Heparin is required for not only Hh-Ihog interactions but also IhogIhog homophilic trans interactions in vitro (McLellan et al. 2006; Zhang et al. 2007; Wu et al. 2019).

The presence of dual functions as an adhesion protein and as a signaling protein is not unique to Ihog proteins. Other members of the Ig-CAM family, such as the netrin receptor DCC, the Slit receptor Robo, and neural cell adhesion molecule (N-CAM), have dual roles. These proteins act as molecular "glue" that holds cells together and as molecular sensors to mediate cellular responses, such as motility, proliferation, and survival (Juliano 2002; Orian-Rousseau and Ponta 2008). However, ligand binding and cell adhesion are often structurally separated and involve different extracellular domains (Frei et al. 1992; Martin-Bermudo and Brown 1999; Sjostrand et al. 2007). In contrast, the Ihog protein couples these distinct functions within the same region. The physiological consequences of coupling two distinct functions into the same region of the Ihog protein are unknown.

In the Drosophila wing imaginal discs, $\mathrm{Hh}$ is secreted in the posterior $(\mathrm{P})$ compartment and spreads toward the anterior (A) compartment (Basler and Struhl 1994; Capdevila et al. 1994; Tabata and Kornberg 1994). Hh signaling does not occur in P compartment cells because they do not express critical components of the Hh pathway, such as the major transcriptional effector Ci (Eaton and Kornberg 1990). In contrast, A compartment cells can receive and respond to $\mathrm{Hh}$ but are unable to produce $\mathrm{Hh}$. In A compartment cells located close to the source of $\mathrm{Hh}$ ligand production at the A/P boundary, Hh signaling triggers pathway activity and, consequently, an increase in the transcription of target genes (Ingham et al. 1991; Basler and Struhl 1994; Capdevila et al. 1994; Tabata and Kornberg 1994; Chen and Struhl 1996). A model of Hh secretion and transport from the basal surface of the Drosophila wing imaginal discs epithelia involves movement of Hh along cytonemes (Gradilla et al. 2014; Chen et al. 2017; Gonzalez-Mendez et al. 2017), which are dynamic thin cellular protrusions specialized for the 
intercellular exchange of signaling proteins (Ramirez-Weber and Kornberg 1999; Roy et al. 2011; Gradilla and Guerrero 2013; Kornberg 2014). Intriguingly, when Ihog is co-expressed with the cytoskeletal and membrane markers of these structures, these thin cellular protrusions are much easier to be detected microscopically (Callejo et al. 2011; Bilioni et al. 2013; Bischoff et al. 2013; Gonzalez-Mendez et al. 2017), which suggests that lhog has roles in generating or stabilizing cytonemes. Moreover, overexpressed lhog is used as a cytoneme marker to visualize these structures (Portela et al. 2019; Gonzalez-Mendez et al. 2020). Yet whether and how Ihog promotes cytoneme growth or stabilization and how cytonemes contribute to Hh transport and signal reception remain poorly understood.

Here, we report that cytoneme-localized lhog proteins engage in trans-homophilic binding leading to cytoneme stabilization in a manner independent of the receptor role of Ihog in transducing the Hh signal. The Ihog-Ihog trans-homophilic binding site overlaps with the IhogHh binding interface and requires the heparin binding site, suggesting direct competition between the dual roles of lhog proteins. By combining experimental data and mathematical modeling, we determined Hh binding to Ihog dominates and can disrupt pre-established lhogIhog trans-homophilic interactions, resulting in Hh-lhog complexes. Our results indicated that the weaker lhog-lhog trans interactions promote and stabilize membrane contacts along the cytonemes and the disruption of some of these interactions by the stronger Hh-lhog interaction could contribute to cytoneme-mediated transport of $\mathrm{Hh}$ or internalization of the ligand-receptor complex. Thus, we proposed that the apparently incompatible functions of Ihog in homophilic adhesion and ligand binding cooperate to assist Hh transport and reception along cytonemes. 


\section{RESULTS}

\section{Ihog stabilizes cytonemes in a manner independent of Hh receptor function}

The Hh receptor component Ihog localizes to cytonemes in the Drosophila wing imaginal discs and abdominal histoblasts. Increasing Ihog abundance makes cytonemes in the histoblasts less dynamic and enables easier microscopic detection of these structures in the wing disc (Callejo et al. 2011; Bilioni et al. 2013; Bischoff et al. 2013; Gonzalez-Mendez et al. 2017). However, it is not clear how ectopic Ihog proteins influence the behavior and morphology of cytonemes. To explore the mechanism by which Ihog proteins affect cytonemes, we transiently expressed Ihog or the actin-binding domain of moesin fused to green fluorescent protein (GFP) (GMA-GFP) in the Hh-receiving cells in the A compartment using a ptc-GAL4 driver in combination with tub-GAL80 ${ }^{\text {ts }}$. Cytonemes projecting from the ptc-GAL4 expressing cells were examined in the $3^{\text {rd }}$ instar larvae wing discs 24 hours after shifting to $29^{\circ} \mathrm{C}$ by staining with antibodies recognizing GFP or Ihog (Fig. 1A). Unlike the short, mostly uniform cytonemes visualized by staining for GMA-GFP, the cytonemes with ectopic expression of Ihog were longer with periodic dense structures (Fig. 1B, C). These dense structures are proposed to represent stable links between Hh-sending and Hh-receiving cytonemes (Gonzalez-Mendez et al. 2017).

Several other Hh pathway components, including the Hh ligands, Ptc, and the Drosophila glypicans Division abnormally delayed (Dally) and Dally-like (DIp), localize to cytonemes (Ayers et al. 2010; Chen et al. 2017; Gonzalez-Mendez et al. 2017). To determine if these effects of Ihog were unique to Ihog, we ectopically expressed each of these components individually using the ptc-GAL4 driver in the wing imaginal disc cells. For these experiments, we included UAS-Myr-RFP, which encodes a myristoylated form of red fluorescent protein, to mark the cell membrane and enable visualization of the cytonemes. Of the tested Hh components, only expression of Ihog lead to formation of the dense structures or increased cytoneme length (Supplementary Fig. 1, Fig. 1A-C). We defined the increased cytoneme length and presence of dense structures as "cytoneme stabilization." 
Previous biochemical and structural studies showed that the Ihog Fn1 domain is involved in binding to the Hh ligand via a heparin-binding surface (McLellan et al. 2006; Yao et al. 2006), whereas the Fn2 of Ihog interacts with Ptc. Both Fn1 and Fn2 domains are required for formation of a high-affinity multimolecular complex of Ihog with Ptc and Hh during Hh signal reception (Zheng et al. 2010). We performed a structure-function analysis by expressing Ihog variants lacking either the first FNIII domain (Fn1) (Ihog $\Delta F n 1)$ or the second Fn2 (lhog $\Delta F n 2)$ or with mutations in the heparin-binding surface $\left(\operatorname{lhog}^{\mathrm{xHep}}\right)$ and quantified the cytoneme-stabilizing effects. These studies revealed that both the increased frequency of dense structures and length of the cytonemes required Fn1 and an intact heparin-binding surface (Fig. 1A - C).

Ptc not only encodes a component of the Hh receptor but is also a transcriptional target of Hh signaling. The highest expression of Ptc is in a stripe of A cells immediately adjacent to the A/P compartment boundary, whereas much lower ptc expression occurs in the $A$ compartment away from the boundary and no expression occurs in the cells of the $\mathrm{P}$ compartment. We generated randomly distributed lhog-overexpressing cells throughout the A and $\mathrm{P}$ compartments in the wing imaginal discs. We observed stabilized cytonemes emanating from with Ihog-expressing clones located not only at the Ptc ${ }^{\text {high }}$ A/P compartment boundary but also within the $\mathrm{Ptc}^{\text {low }} \mathrm{A}$ compartment and $\mathrm{Ptc}^{\text {neg }} \mathrm{P}$ compartment (Fig. 2A, upper row). Thus, the cytoneme-stabilizing effect of Ihog was independent of Ptc, consistent with the ability of Ihog lacking the Fn2 domain to perform this function. Moreover, the expression of Ptc-binding deficient lhog $\Delta \mathrm{Fn} 2$ in the A/P boundary cells resulted in stable cytonemes projecting both posteriorly towards the Hh-secreting $\mathrm{P}$ cells and anteriorly away from the Hh source (Fig. 2B). These observations indicated that Ihog stabilizes cytonemes through a mechanism different from that used for the formation of Ihog-Ptc receptor complex, which exhibits high-affinity binding to Hh ligands.

In the wing imaginal discs, $\mathrm{Hh}$ is secreted from the $\mathrm{P}$ compartment and there is little to no Hh that diffuses several cell diameters into the A compartment (Zecca et al. 1995; Mullor et 
al. 1997; Strigini and Cohen 1997). Ihog interacts with Hh both in the context of the Ihog-Ptc complex and independently from Ptc (McLellan et al. 2006; Yan et al. 2010; Zheng et al. 2010). We reasoned that, if Ihog Fn1-mediated binding to Hh contributes to the cytoneme-stabilizing effect, cytonemes projecting from the lhog-expressing wing disc cells in the A or P compartment should display different properties. Consistent with Ihog interacting with Hh, Hh staining colocalized with Ihog-expressing cytonemes either projecting from clones located within the $\mathrm{P}$ compartment or from boundary clones projecting posteriorly toward the Hh source (Fig. 2A, lower row). No or very little Hh staining was detected with lhog-expressing cytonemes from clones within the A compartment or with lhog-expressing cytonemes from clones at the A/P boundary and extending into the A compartment. Despite the absence or limited amount of Hh ligands, Ihog expression stabilized all the cytonemes projecting within or toward the A compartment. These results indicated that Ihog Fn1-mediated binding to Hh ligands did not account for the stable cytonemes visualized by ectopic lhog expression in the wing imaginal disc cells.

Quantification of cytoneme length and the number of dense structures per cytoneme for Ihog-expressing clones in the A compartment, P compartment, and at the boundary showed that cytoneme stabilization by Ihog was independent of position within the wing disc and thus the abundance of Ptc or Hh ligands (Fig. 2C, D). We also quantified cytoneme-stabilizing properties for Ihog $\Delta \mathrm{Fn} 2$ in flip-out clones located close to the A/P compartment boundary, which also showed no difference between cytonemes projecting posteriorly towards the Hh-secreting P cells and those projecting anteriorly away from the Hh source (Fig. 2E, F). Collectively, our results indicated that neither the presence of Ptc nor Hh is necessary for Ihog-mediated cytoneme stabilization. This function of Ihog was separate from its function in the Hh receptor.

\section{Ihog facilitates cytoneme stabilization through homophilic trans binding supported by glypicans}


Previously, we showed that the Ihog Fn1 domain not only plays an essential role in Hh signal transduction but also mediates cell-cell interactions in a homophilic manner (Hsia et al. 2017; Wu et al. 2019). Because our data indicated that Ihog stabilized cytonemes through the Fn1 domain in a manner independent of Hh receptor function (Fig. 1, 2), we hypothesized that Ihog Fn1-mediated homophilic trans interactions were responsible for cytoneme stabilization. The region that we identified as mediating the trans Ihog-lhog interaction overlaps with the region that mediates the interaction with $\mathrm{Hh}$ on the Ihog $\mathrm{Fn} 1$ domain and includes a region where the negatively charged glycan heparin binds (McLellan et al. 2006; Wu et al. 2019). In vitro, heparin is required for not only lhog-Hh binding but also Ihog-lhog homophilic trans interactions (McLellan et al. 2006; Wu et al. 2019). Thus, a model for Ihog-Ihog homophilic trans interactions involves heparin-dependent bridging of positively charged surfaces on the two opposing Fn1 domains, in a manner similar to heparin-bridged lhog-Hh interactions (McLellan et al. 2006; Wu et al. 2019).

Heparin used in previous in vitro assays is an intracellular glycosaminoglycan (GAG) that is not present on the cell surface or along the cytonemes. Thus, heparin is unlikely to mediate Ihog-lhog trans interactions in vivo. Heparan sulfate, which is an extracellular GAG structurally related to heparin and ubiquitously located on the cell surface or in the surrounding extracellular matrix, was subsequently found to supply the function of heparin and mediate lhogHh interaction in vitro (Zhang et al. 2007). Heparan sulfate is also covalently attached to proteins forming heparan sulfate proteoglycans (HSPGs), thus, heparan sulfate or HSPGs may serve as the physiological correlate of heparin to mediate Ihog-Ihog homophilic trans binding and Ihog-Hh binding. Dally and DIp are two Drosophila glycosylphosphatidylinositol (GPI)anchored HSPGs, which can be membrane-tethered or released from cells upon cleavage (Bernfield et al. 1999). Dally and DIp are known to be involved in modulating the transport and reception of the Hh signal (Lum et al. 2003; Lin 2004; Tabata and Takei 2004; Eugster et al. 2007; Ayers et al. 2010; Yan et al. 2010; Bilioni et al. 2013). Ihog-expressing cytonemes rarely 
extend across large clonal populations of dally and dlp double mutant cells (Gonzalez-Mendez et al. 2017), indicating that Dally and Dlp could be the major source of heparan sulfate that enables Ihog-Ihog homophilic trans interactions in vivo. Consistent with this hypothesis, we detected a striking accumulation of endogenous Dlp along lhog-expressing cytonemes not only in the P compartment or along the A/P boundary where both Ihog-Hh and Ihog-lhog interactions exist (Fig. 3A) but also within the A compartment that lacks Hh and where only lhog-lhog homophilic interactions could occur (Fig. 3B). Additionally, Dlp accumulated along the apical and lateral cell-cell contacts (Fig. 3B; yellow outlined regions), where homophilic Ihog trans binding contributes to cell segregation in the wing imaginal disc epithelium (Hsia et al. 2017; Wu et al. 2019). We also observed that ectopic expression of Ihog caused the accumulation of endogenous Dally along the apical and lateral cell-cell contacts and basal cytonemes (Supplementary Fig. 2).

The Ihog-induced accumulation of Dally and DIp along the basal cytonemes is consistent with a crucial contribution of either Dally or Dlp in Ihog-mediated cytoneme stabilization (Gonzalez-Mendez et al. 2017). However, ectopic expression of neither Dally nor Dip resulted in cytoneme stabilization in the wing discs (Supplementary Fig. 1). Thus, the roles of Ihog and the glypicans in stabilizing the cytonemes are different. Given the known function of heparin as a bridging molecule in Ihog-Ihog or Ihog-Hh interactions, our results suggested that the heparan sulfate chains of Dally or Dlp provide this function in Ihog-lhog trans interactions. Consistent with this model, the Ihog-induced Dally or Dlp accumulation reflected the different distributions of the two glypicans. DIp is distributed in most cells, except in a zone $\sim 7-10$ cell diameters in width and centered at the dorsal ventral (D/N) boundary. Dally is also broadly distributed; however, Dally abundance is highest along the D/V boundary (Fujise et al. 2001; Fujise et al. 2003; Han et al. 2005). In agreement with these different distributions, both Dally and Dlp were enriched along the cytonemes and at the apical and lateral cell contacts of lhog-expressing cells away from the D/V boundary, whereas the lhog-expressing cells flanking the D/V boundary 
were positive for Dally with little or no detectable DIp (Fig. 3B, blue outline; Supplementary Fig. 2). Similar to the Ihog-mediated homophilic binding, Ihog-induced Dlp accumulation occurred in the absence of the Ihog Fn2 domain (Fig. 3A). In contrast, neither ectopic expression of Ihog $\Delta \mathrm{Fn} 1$ nor $\operatorname{lhog}^{\mathrm{xHep}}$, both of which lack homophilic binding capability, resulted in the accumulation of DIp (Fig. 3A). Taken together, these results indicated that Ihog Fn1-mediated homophilic trans interactions, assisted by the heparan sulfate chains of Dally or DIp in the wing imaginal discs, contribute to cytoneme stabilization.

\section{Homophilic Ihog trans interactions promote direct cytoneme-cytoneme contact formation}

We previously found that ectopic expression of Ihog in the non-adherent Drosophila S2 cells induces cell aggregation via homophilic trans-interactions (Wu et al. 2019). Pairs of lhogpositive S2 cells in close contact (aggregated) showed a peak of Ihog positivity along the site of cell-cell contact (Supplementary Fig. 3A-C, Supplementary movies 1, 2). In contrast, Ihog was enriched in filopodia-like structures on dispersed S2 cells when evaluated for live cells or fixed cells (Supplementary Fig. 3D-G, Supplementary movies 3, 4). Because Drosophila S2 cell filopodia recapitulate structural and functional characteristics of cytonemes in the imaginal disc (Bodeen et al. 2017), here, we take advantage of these dispersed lhog-expressing S2 cells to evaluate the possibility of filopodia-localized lhog proteins in participating homophilic transinteractions. We examined the behavior of these Ihog-positive filopodia between an Ihogpositive cell and an lhog-negative cell and between pairs of lhog-positive cells. These structures were found at regions where two Ihog-positive cells were in close apposition with the filopodia projecting toward the adjacent Ihog-positive cell (Supplementary Fig. 4A). In contrast, an Ihogpositive cell extend fewer filopodia toward an Ihog-negative cell (Supplementary Fig. 4A, B). Two closely positioned lhog-positive cells exhibited an increase in the number of filopodia oriented toward the nearby Ihog-positive cell (Supplementary Fig. 4C). Moreover, using live-cell time-lapse imaging, we observed that the nearby cells that were both positive for Ihog became 
closer as the Ihog-positive filopodia became more interdigitated (Supplementary Fig. 5). Collectively, the observations in S2 cells suggested that filopodia-localized Ihog proteins engaged in homophilic trans binding evidenced by the contact initiation among non-adjacent lhog-expressing S2 cells.

To explore if such events occurred in vivo, we generated lhog-expressing clones in the wing imaginal discs and found that cytonemes projecting from closely positioned clones appeared to come into contact (Figs. 4A; arrows). Unlike cultured S2 cells, the wing imaginal disc epithelial cells tightly adhere to their immediate neighbors and maintained stable cellneighbor relationships (Garcia-Bellido et al. 1973; Gibson et al. 2006). Cytoneme-cytoneme interaction is unlikely to lead to move the cell body, thus a reduction in the distance between non-adjacent Ihog-expressing clones could not be used as the functional readout of Ihog-Ihog trans-interaction along the cytonemes. Therefore, we examined whether direct membrane contacts were established along Ihog-localized cytonemes.

Membrane contacts are typically separated by less than $100 \mathrm{~nm}$ of extracellular space, which is below the resolution of conventional light microscopy. To examine whether membrane contacts were established along Ihog-stabilized cytonemes, we combined the CoinFLPLexGAD/GAL4 system and the GFP Reconstitution Across Synaptic Partners (GRASP) system (Feinberg et al. 2008; Gordon and Scott 2009; Bosch et al. 2015). CoinFLP-LexGAD/GAL4 allows generation of tissues composed of clones that express either GAL4 or LexGAD, thus enabling the study of interactions between different groups of genetically manipulated cells (Bosch et al. 2015). In the GRASP system, two complementary parts of a 'split GFP' (spGFP ${ }_{1-10}$ and spGFP 11 ) are fused to the extracellular domains of mouse CD4, one under UAS control and the other under LexAop control. Whereas individually the membrane-tethered spGFP fragments are not fluorescent, reconstitution of GFP generates fluorescence at the boundary of immediately adjacent clones that express the complementary spGFP fragments (Bosch et al. 2015). We expressed RFP-tagged Ihog together with CD4-spGFP ${ }_{1-10}$ and HA-tagged Ihog $\Delta$ Fn2 
with CD4-spGFP 11 . With this system, we monitored cells for the presence of either lhog or Ihog $\Delta \mathrm{Fn} 2$ using an antibody recognizing lhog and cells positive for only lhog $\Delta \mathrm{Fn} 2$ using an antibody against the HA tag.

As expected from the CoinFLP system, clones expressing lhog-RFP plus CD4-spGFP ${ }_{1}$ 10 and those expressing lhog $\Delta \mathrm{Fn} 2-\mathrm{HA}$ plus $\mathrm{CD}_{4}-\mathrm{sp} \mathrm{GFP}_{11}$ were randomly distributed in the wing imaginal discs. When these two types of clones were located immediately adjacent to each other, GRASP fluorescence was detected both at the apical lateral contacts and along the basal cytonemes of the adjacent cells expressing Ihog-RFP plus UAS-CD4-spGFP ${ }_{1-10}$ or Ihog $\Delta$ Fn2-HA plus LexAop-CD4-spGFP 11 (Fig. 4B, C, D; blue outline and blue arrow). The basal cytonemes emanating from wing imaginal disc cells can reach as far as several cell diameters, thus, if cytoneme-localized Ihog proteins participate in homophilic trans-binding, direct cytonemecytoneme contacts from non-adjacent cells could be preferentially established among these cytonemes expressing ectopic Ihog proteins. Indeed, GRASP fluorescence also appeared along the length of the cytonemes projecting from the non-adjacent Ihog-RFP plus UAS-CD4-spGFP 1 10 and Ihog $\Delta$ Fn2-HA plus LexAop-CD4-spGFP 11 expressing cells that do not share common boundaries as indicated by lacking of GRASP florescence throughout the apical and lateral clonal borders (Fig. 4B, C, D; yellow outline and yellow arrow). Therefore, the GRASP marked cytoneme-cytoneme contacts from non-adjacent clones suggested that membrane contacts were initiated and established along lhog-expressing cytonemes, supporting the idea that lhogIhog trans-binding can occur along opposing cytoneme membranes in vivo.

\section{Modeling predicts that homophilic Ihog trans interactions increase cytoneme length and bundling}

We developed a stochastic model to investigate the influence of the homophilic transinteraction strength on the dynamics of cytonemes. In the model, cytonemes were represented as filamentous structures with variable numbers of discrete segments. We considered the 
elongation, shrinkage, translocation, and interaction events of cytonemes around the cell surface: An elongation or shrinkage event was represented by the addition or removal of one segment to or from an existing cytoneme; a translocation event was represented as the movement of a cytoneme along the cell surface; and interaction events of two cytonemes in contact were represented by pairwise interactions between segments.

We set the elongation probability of the $i^{\text {th }}$ cytoneme to exponentially decay with its length:

$$
p_{\text {elongation }, i}=p_{\text {elongration }}^{0} \times e^{-\alpha \cdot x_{i}}
$$

where $p_{\text {elongation }}^{0}$ is the base elongation probability at the cell surface, $\alpha$ is the decay coefficient, and $x_{i}$ is the number of segments in the $i^{\text {th }}$ cytoneme (that is the length that the cytoneme extended from the cell surface). This decay relationship represents the increasing difficulty in transporting materials to the tip of the cytoneme as elongation occurs and increasing difficulty in the occurrence of elongation as the membrane tension increases, thereby resisting elongation.

The shrinkage rate at the tip of the $i^{\text {th }}$ cytoneme is modeled as

$$
p_{\text {shrink }, i}=p_{\text {shrink }}^{0} \times e^{-T_{i} \cdot E_{i i}}
$$

where $p_{\text {shrink }}^{0}$ is the intrinsic shrinkage rate without any homophilic trans interaction, $E_{i i}>0$ is the strength of the homophilic trans interaction between a pair of segments, and $T_{i}$ is the number of neighboring cytonemes with which this $i^{\text {th }}$ tip segment interacts. Thus, the homophilic trans interactions at the tip segment represent additional energy barriers to a shrinkage event.

To enhance simulation efficiency, we employed the quasi-equilibrium approximation (Goutsias 2005) to simulate the pairwise interactions between segments on neighboring cytonemes. First, we computed the probability of establishing a homophilic trans interaction between a pair of neighboring cytoneme segments:

$$
p_{\text {interaction }}=\frac{\exp \left(E_{i i}\right)}{1+\exp \left(E_{i i}\right)}
$$


Based on $p_{\text {interaction }}$, we randomly assigned a binary state variable, $s_{k}^{i, j}(0$ for not interacting, 1 for interacting), to the $k^{\text {th }}$ pair of neighboring segments in the $i^{\text {th }}$ and $j^{\text {th }}$ cytonemes for each simulation step. Thus, the total homophilic interactions of the $i^{\text {th }}$ cytoneme is calculated as

$$
E_{\text {interaction }}^{i}=E_{i i} \times \sum_{j \in \text { neighbor of } i} \sum_{k} s_{k}^{i j}
$$

The cytonemes can also translocate along the cell periphery. A translocation event involves breaking the existing homophilic trans interactions and establishing new homophilic trans interactions. We computed the differences in the trans interactions before and after a

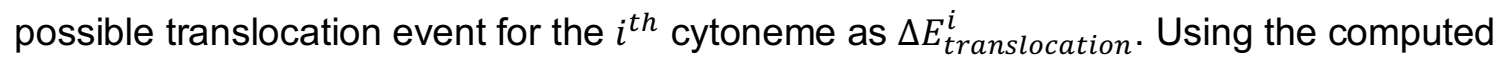
probabilities and energy differences, we performed stochastic simulations and collected the cytoneme configurations after the simulations reached steady state (see Methods for details).

We simulated the system with no $\left(E_{i i}=0\right)$ homophilic trans interactions (Fig. 5A, left) and with homophilic trans interactions of moderate strength $\left(E_{i i}=15\right)$ (Fig. 5A, right). Without any homophilic trans interactions, the simulations resulted in much fewer numbers of segments (shorter cytoneme length). For $E_{i i}=15$, the simulations predicted more variability in the length of cytonemes than was predicted at $E_{i i}=0$. By capturing 1001 snapshots from the random simulations for $E_{i i}=0$ and 15 , we found that the simulations produced cytoneme lengths that were significantly longer at $E_{i i}=15$ (Fig. 5B). Additionally, the number of established pairwise interactions between cytonemes greatly increased at $E_{i i}=15$ (Fig. 5C). Thus, the simulations indicated that cytoneme length correlated with the number of cytoneme-cytoneme interaction events (Fig. 5D, Pearson $r=0.7939$ ). By varying the strength of homophilic trans interactions, we also found that average cytoneme length increased with stronger cytoneme-cytoneme interactions (Fig. 5E).

In the snapshots of the simulations, we observed extensive pairwise interactions among adjacent cytonemes only when we set $E_{i i}>0$ (Figs. 5A, arrows). We defined this phenomenon as "cytoneme bundling" and quantified this phenomenon with a cytoneme bundling index (see 
Methods). The cytoneme bundling index increased as the strength of the homophilic trans interactions among cytonemes increased (Fig. 5F). Furthermore, with increasing cytonemecytoneme homophilic trans-interaction strength $E_{i i}$, we observed a decreased proportion of singular cytonemes and an increased proportion of cytonemes within the cytoneme bundles (Supplementary Fig. 6). These results predicted that cytonemes of Ihog-overexpressing cells would form extensive contacts and appear as bundles. By regular confocal microscopy, we observed an increase in dense contact sites, but we did not detect clear evidence of cytoneme bundles in the lhog-overexpressing wing disc. This is likely because the diameter of cytonemes [100-200 nm (Mattila and Lappalainen 2008; Kornberg 2014)] is much less than the resolution limit ( 250 nm laterally) of confocal microscopy. We used Airyscan technology, which has a lateral resolution of $120 \mathrm{~nm}$ (Huff 2015)., to test the prediction of Ihog-induced bundling of cytonemes in the wing disc. We imaged lhog-expressing cytonemes in wing discs cells colabeled with membrane marker glycosyl-phosphatidyl-inositol-YFP (Greco et al. 2001) (GPIYFP, Fig. 5G) . Consistent with the computational modeling prediction, we detected sites of cytoneme-cytoneme contact (Fig. 5G, yellow arrows) and thin cytonemes (Fig. 5G, blue arrows) that appeared to form thick bundles (Fig. 5G, red arrows). In contrast, we rarely observed cytoneme bundling upon expression of only the membrane marker GPI-YFP or expression of the homophilic binding-deficient Ihog variants $\operatorname{lhog} \Delta \mathrm{Fn} 1$ and $\operatorname{lhog}^{\mathrm{xHep}}$ (Supplementary Fig. 7). Also consistent with the model predictions, we found that knockdown of ihog in the absence of its close paralog-encoding gene boi resulted in cytonemes with significantly reduced length compared with the length of cytonemes in boi mutant animals retaining normal expression of Ihog (Supplementary Fig. 8). Thus, the in vivo observations supported the predictions from the computational modeling that the augmented cytoneme-cytoneme interactions mediated by ectopic Ihog lead to elongated and bundled cytonemes.

\section{Heterophilic Ihog-Hh binding dominates over homophilic Ihog trans interaction}


A single Ihog protein can participate in either an Ihog-lhog trans interaction or an Ihog-Hh interaction; therefore, a single Ihog protein can mediate either its cytoneme-stabilizing function or its ligand-binding function, but not both simultaneously. The dissociation constant for the nonlipid-modified recombinant $\mathrm{HhN}$ and the extracellular portion of Ihog containing the Fn1 and Fn2 domains (IhogFn1-2), measured in solution, is $2 \mu \mathrm{M}$ (McLellan et al. 2006; Zhang et al. 2007). Additionally, soluble $\mathrm{HhN}$ at $30 \mu \mathrm{M}$ competes for Ihog homophilic interactions in a pulldown assay in which $\mathrm{HhN}$ and Ihog are mixed simultaneously (Wu et al. 2019). To explore the interaction hierarchy of Ihog-Ihog trans interactions and Ihog-Hh interactions, we used the S2 cell system. Ihog-Ihog trans interactions result in aggregation of the normally non-adhesive S2 cells (Hsia et al. 2017; Wu et al. 2019). We performed lhog-mediated cell aggregation assays with two populations of cells, one expressing Ihog and GFP and the other expressing Ihog and mCherry, in the presence of exogenously applied recombinant HhN. Unexpectedly, even at 30 $\mu \mathrm{M}$, a concentration 10 times higher than the reported dissociation constant, soluble $\mathrm{HhN}$ had little effect on Ihog-mediated cell aggregation (Supplementary Fig. 9). One explanation is that soluble $\mathrm{HhN}$ does not reach a sufficiently high concentration at the cell surface to compete for the extensive homophilic trans interactions that can be mediated by membrane-tethered Ihog proteins. Thus, we developed a system to test the ability of plasma membrane-associated Hh to interfere with Ihog-Ihog trans interactions. Expression of cDNA encoding full-length Hh in S2 cells generates dually lipid-modified Hh ligands, whereas expressing cDNA encoding the aminoterminal signaling fragment results in HhN lacking a cholesterol modification (Burke et al., 1999; Porter et al., 1995). Although both forms of Hh ligands are competent to bind to the receptors and induce $\mathrm{Hh}$ signaling in ligand-receiving cells, $\mathrm{HhN}$ does not require Dispatched (Disp) for release from the producing cell. Thus, in S2 cells without also ectopically expressing Disp, only dually lipid-modified $\mathrm{Hh}$ ligands resulted from cDNA encoding the full-length $\mathrm{Hh}$ and this lipidmodified Hh was enriched at the surface of the transfected cells (Supplementary Fig. 10). Using 
these cells, we assessed the relative strengths of Ihog-mediated ligand binding and homophilic trans interactions.

A heterogeneous aggregation of cells exhibits distinct morphological patterns when the relative strengths of the heterotypic and homotypic cell-cell adhesions differ. For example, a checkerboard-like pattern can occur when heterotypic cell-cell adhesions dominate (Honda et al. 1986). Therefore, we hypothesized that the morphological patterns produced by the aggregated $\mathrm{Hh}$ - and lhog-expressing cells reflect the relative affinity of Ihog-Hh (heterotypic) and Ihog-Ihog (homotypic) interactions. To test this hypothesis, we prepared S2 cells expressing $\mathrm{Hh}$ or $\mathrm{HhN}$ and cells expressing Ihog, along with either GFP or monomeric Cherry (mCherry), mixed the cells, and assessed the pattern of the aggregated clusters (Fig. 6). We found that Hh-expressing cells remained dispersed when cultured by themselves (Fig. 6A, mCherry $+\mathrm{Hh}, \mathrm{GFP}+\mathrm{Hh}$ ) and aggregated when mixed with Ihog-expressing cells (Fig. 6A, mCherry+lhog, GFP+Hh). In contrast, $\mathrm{HhN}$-expressing cells remained dispersed when cultured by themselves (Fig. 6A, mCherry+HhN, GFP+HhN).

When HhN-expressing cells were cocultured with lhog-expressing cells, only the lhogexpressing cells clustered (Fig. 6A, mCherry+lhog, GFP+HhN). We compared the patterns of the cells in the clusters containing only lhog-expressing cells and those containing both lhogexpressing cells and Hh-expressing cells. We observed a checkerboard-like pattern with evenly distributed red and green cells in aggregates formed by cells expressing Hh with GFP and cells expressing lhog with mCherry (Fig. 6B). Most center cells within the cell aggregates had 4 or 5 neighbors (Fig. 6C). Furthermore, among those neighbors, cells expressing the same transfected proteins and thus of the same color ("like" cell) were rare (Fig. 6B, D). In contrast, aggregates of Ihog-expressing cells labeled with either GFP or mCherry exhibited a honeycomb pattern (Fig. 6B): Most center cells had 5 or 6 neighbors (Fig. $6 \mathrm{C}$ ), and $\sim 50 \%$ were "like" cells (Fig. 6B, D). For each aggregation assay, we confirmed by immunoblotting that transfected cells from the same experiment used for the aggregation assays expressed comparable amounts of 
Ihog and Hh proteins (Supplementary Fig. 11). Therefore, the different cellular patterns formed by cells expressing $\mathrm{Hh}$ and cells expressing lhog versus those formed by differentially labeled Ihog-expressing cells suggested that the heterophilic interaction between Ihog and $\mathrm{Hh}$ is stronger than the homophilic trans interaction between Ihog proteins on an opposing cell surface.

\section{Computational modeling estimates the difference in strength between the heterophilic Ihog-Hh and homophilic Ihog trans interaction}

Directly determining the affinities of the homophilic and heterophilic interactions is difficult because the affinities depend on the conformation of the lhog dimers (trans-interacting or cis-interacting) and the membrane association of Hh. Thus, we took a computational approach to estimate the relative affinities of these two lhog interactions. Motivated by the observations that cells expressing $\mathrm{Hh}$ and lhog produced a different pattern from the cells expressing Ihog, we estimated the difference in strength between the heterophilic Ihog-Hh and homophilic lhog-lhog trans interactions by modeling these interactions using a vertex-based in silico assay (Bi et al. 2015; Park et al. 2016). We explicitly included heterogeneous cell composition in our model in the following manner: The cells were approximated by polygons that can freely change their locations and shapes. Consequently, two interacting cells were represented by two polygons sharing a common edge. This interaction leads to an energy reduction, the magnitude of which depends on various properties including the strength of the cell-cell adhesive interactions. From the cell shapes and configurations of neighboring cells, mechanical energy $\left(e_{i}\right)$ was calculated for each cell according to (Farhadifar et al. 2007) as:

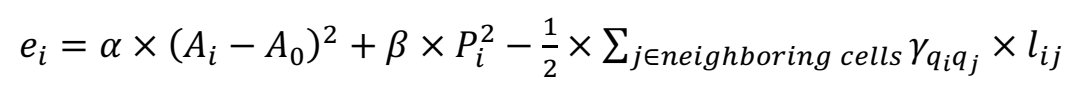

The first term is the areal elasticity, which is represented by $\alpha$ (the elastic coefficient), $A_{i}$ (the area of the $i$ th cell), and $A_{0}$ (the preferred cell area). The second term is the contractile 
energy, which is represented by $\beta$ (the contractile coefficient) and $P_{i}$ (the perimeter of the $i$ th cell). The third term is the net adhesive energy between the $i$ th cell and its neighbors, where $\gamma_{q_{i} q_{j}}$ is the line density of the adhesive energy between cell types $q_{i}$ and $q_{j}$, and $l_{i j}$ is the length of the common edge between the two cells. We have $\gamma_{I I}, \gamma_{I H}$, and $\gamma_{H H}$, depending on the types of surface proteins expressed by the cells: both expressing lhog, $I I$, or one expressing Ihog and one expressing $\mathrm{Hh}, \mathrm{IH}$. Here, $\gamma_{H H}=0$, because we did not observe cells both expressing $\mathrm{Hh}$ in contact with each other in the aggregation assays.

We used the Monte Carlo method (Metropolis 1953) to simultaneously simulate 100 cells within a 2-dimensional space. Gaps between cells were simulated as empty polygons that do not contribute to the mechanical energy of the system. With this system, the aggregation or segregation of cells is governed by $\sum e_{i}$. As a control, we simulated 100 Ihog-expressing cells with half labeled red and half labeled green, which produced a honeycomb morphological pattern (Fig. 7A), within which a given center cell had $5.8 \pm 0.6$ neighbors, and $2.4 \pm 0.9$ of them had the same color label as the center cell (Fig. 7C, I I bars).

We simulated 50 lhog-expressing cells and 50 Hh-expressing cells (Fig. 7B). When we altered the ratio of the heterotypic and the homotypic interaction strength $\left(\gamma_{I I}, \gamma_{I H}\right.$ values), the morphology of the mixed system changed. From these values and the patterns, we obtained the average number and type of neighbor cells for any given center cell. We found that when $\gamma_{I H}$ is 30 times larger than $\gamma_{I I}$, the mixed system exhibited the checkerboard-like morphological pattern (Fig. 6B), within which each center cell had $4.1 \pm 0.7$ neighbors, and only $0.3 \pm 0.5$ of them were "like" cells (Fig. 7C, I H bars).

This simulation study of the effect of the parameter $\gamma_{I I}: \gamma_{I H}$ predicted that the number and type of neighbor cells are sensitive to the $\gamma_{I H}: \gamma_{I I}$ ratio. A honeycomb-to-checkerboard transition occurred when $\gamma_{I H}: \gamma_{I I}$ is between 20 and 30 (Fig. 7D, E). Therefore, the neighbor statistics from the experimental aggregation assay and the computational modeling suggested 
that the relative affinity of the Ihog-Hh heterotypic interaction is at least $\sim 20-30$ times higher than that of the Ihog-Ihog homotypic trans interaction. Previous sedimentation velocity and sedimentation equilibrium experiments predicted that the dimerization constants for the extracellular portion of Ihog comprising Fn1-2 range from 60 to $430 \mu \mathrm{M}$ and that the dissociation constants for the interaction between $\mathrm{HhN}$ and this IhogFn1-2 region were between $0.4-8.0 \mu \mathrm{M}$ (McLellan et al. 2006; Zhang et al. 2007).. Although we cannot differentiate homophilic cis interactions from homophilic trans interactions, our modeling prediction of an affinity for the Ihog-Hh heterotypic interaction that is at least 20 times higher than that for the Ihog-Ihog homotypic trans interaction is consistent with the values obtained in the biochemical experiments (McLellan et al. 2006; Zhang et al. 2007).

\section{Heterophilic Ihog-Hh binding displaces pre-established homophilic Ihog trans interactions}

Differential adhesion has been proposed to promote cell rearrangements in cell aggregates such that strongly adhesive cells sort together and weakly adhesive cells are excluded (Foty and Steinberg 2005; Steinberg 2007). Thus, from our computational analysis of interaction strength, we predicted that mixing Hh-expressing cells with pre-existing aggregates of Ihog-expressing cells would displace the relatively weaker Ihog-mediated homophilic interactions by establishing stronger Hh-lhog interactions and result in a checkerboard pattern. To test this, we performed both computational model simulations and experiments with S2 cells. With $\gamma_{I H}: \gamma_{I I}=30$ in the computational model, we observed the development of the checkerboard pattern as the simulation reached steady state (Fig. 7F).

In the S2 cell experiment, we mixed differentially labeled Hh-expressing cells with preformed aggregates of lhog-expressing cells (Fig. 7G). Within 30 minutes after cell mixing, Hh-expressing cells were found on the surface of the pre-existing aggregates of lhogexpressing cells, which we interpreted as $\mathrm{Hh}$ binding to lhog proteins that were not engaged in 
homophilic adhesion. Over time, Hh-expressing cells were found inside the lhog-expressing cell aggregates, such that, by 12 hours after mixing, all cell aggregates contained similar numbers of Hh-expressing cells and lhog-expressing cells arranged in a checkerboard-like pattern (Fig.

$7 G)$. This pattern is consistent with cell rearrangements caused by differential adhesion with the Hh-Ihog interaction exhibiting a higher affinity than the Ihog-Ihog homophilic trans interaction.

Moreover, the observed cellular rearrangement indicated the Hh ligand disrupts trans Ihog-Ihog binding by competing for the Ihog Fn1 domain. Taken together, these results suggested Hh binding to Ihog is dominant over Ihog-Ihog homophilic interactions and effectively competes for Ihog even in the context of pre-established Ihog-Ihog trans-homophilic interactions. 


\section{DISCUSSION}

We investigated the functional roles of the Hh receptor lhog by determining a mechanism by which the Ihog proteins stabilizes cytonemes in the Drosophila wing imaginal disc. We found a dual role for cytoneme-localized lhog proteins in Hh signal transduction and in trans-homophilic binding that mediates cytoneme-cytoneme interactions. This dual function is not unique to the Ihog proteins. Like Ihog, other members of the Ig-CAM family, such as the netrin receptor DCC, the Slit receptor Robo, and neural cell adhesion molecule N-CAM, also have dual roles in adhesion and signaling (Juliano 2002; Orian-Rousseau and Ponta 2008). The ligand binding and cell adhesion functions often involve different extracellular domains of the same protein, thus are biochemically separated and mutually compatible (Frei et al. 1992; Martin-Bermudo and Brown 1999; Sjostrand et al. 2007). However, the Ihog homophilic binding site overlaps with Ihog-Hh interface on $\mathrm{Fn} 1$ of the Ihog extracellular domain, resulting in competition between Hh binding and lhog-Ihog interactions.

On the basis of these two functions competing for an overlapping surface on the lhog Fn1 domain and the differential interaction strength between Ihog-Hh heterophilic and Ihog-lhog trans-homophilic bindings, we propose a model in which lhog-lhog trans interactions promote and stabilize direct cytoneme-cytoneme contacts to facilitate Ihog in reaching and capturing the Hh ligands secreted from the cytonemes. The stronger ligand-receptor interaction releases Ihog from the weaker trans-homophilic interaction, enabling the receptor-ligand complex to freely transport or become internalized along the cytonemes. Meanwhile, the unbound former homophilic binding-partner Ihog either forms a new homophilic contact or engages in ligandreceptor complex formation along the cytonemes (Fig. 8). Thus, the apparently incompatible functions of Ihog in homophilic adhesion and ligand binding cooperate to promote Hh transport and reception along the cytonemes. The model incorporates the role of the glypicans, DIp and Dally. Although contrary to a previous model that limited the contribution of the glypicans in cytoneme stabilization to a trans role (Gonzalez-Mendez et al., 2017), in our model DIp or Dally 
can contribute either as the membrane-tethered or the shed form and participate Ihog-lhog trans interactions. Our model is also consistent with the reported affinity of $\mathrm{Hh}$ for the Ihog-Ptc receptor complex, which is higher than the affinity of Hh for the co-receptor Ihog alone (Zheng et al. 2010). Indeed, the presence of Ptc in the Hh-receiving cytoneme is critical to Hh reception in the responding cells (Chen et al. 2017). Thus, we propose that the integration of the functions of Ihog — promotion of cytoneme-cytoneme contacts, Hh delivery, and Hh signal reception depends on the differential affinity (Ihog-lhog $<$ Ihog-Hh $<$ Ptc-lhog-Hh) and the competitive binding between Ihog for itself (in trans) and Hh (Fig. 8).

The trans-homophilic Ihog-Ihog interaction is not only critical for cytoneme stabilization but also for A/P compartment boundary maintenance in the Drosophila wing discs (Hsia et al. 2017). Notably, both Hh release and cytoneme formation occurs at the basal side of the wing disc epithelium (Callejo et al. 2011; Bilioni et al. 2013; Bischoff et al. 2013; Gradilla et al. 2014; Chen et al. 2017; Gonzalez-Mendez et al. 2017), making weaker Ihog-Ihog trans interactions accessible for replacement by stronger Ihog-Hh interactions along the cytonemes, where Ihog also functions as the receptor for $\mathrm{Hh}$ transport and reception (Fig. 8). In contrast, farther from the source of secreted $\mathrm{Hh}$, heterophilic lhog-Hh interactions would be infrequent along the lateral side of epithelia, where the trans Ihog-Ihog interactions play essential roles in modulating A/P cell segregation and lineage restriction (Hsia et al. 2017). In addition, direct membrane contacts are much more extensive along the lateral sides of epithelia compared with that formed along cytonemes (Fig. 5), favoring persistent Ihog-Ihog trans interactions that create an additional barrier for direct competition from the basally released $\mathrm{Hh}$ ligands. Thus, in agreement with the functional needs and the availability of Hh ligands, Ihog-lhog homophilic trans interactions along the cytonemes are dynamic and readily switchable, whereas those at the lateral cell-cell junctions are more stable and less likely to be disrupted (Fig. 8).

Beside the wing imaginal disc epithelia, cytoneme-mediated $\mathrm{Hh}$ reception and transport has been described in other Drosophila tissues, such as the abdominal and the female germline 
stem cell niche (Rojas-Rios et al. 2012; Bischoff et al. 2013; Gonzalez-Mendez et al. 2017). The involvement of cytonemes in Hh signaling has been extended from insect to vertebrates by studies of the limb bud of chick embryo and cultured mouse embryonic fibroblasts (Sanders et al. 2013; Hall et al. 2020). The vertebrate homologs of the Drosophila Ihog proteins, Cdo and Boc, localize in cytonemes, and overexpression of either CDO or BOC increases the number of cytonemes detected on mammalian cells (Hall et al. 2020). Furthermore, cytonemes have been implicated in the delivery of other paracrine signaling molecules important in development, including Notch, epidermal growth factor, fibroblast growth factor, bone morphogenetic protein, and Wnt (Gonzalez-Mendez et al. 2019). Remarkably, cytonemes from a single cell often exhibit different receptor compositions such that different cytonemes from the same cell can selectively respond to ligands for a specific pathway and not others (Roy et al. 2011). The mechanism that segregates receptors to different cytonemes is yet not known. Whether homotypic adhesion contributes to the distinct localization of morphogen receptors to different cytoneme remains an open question. Further studies are necessary to explore whether the vertebrate Hh co-receptors $\mathrm{CDO}$ and $\mathrm{BOC}$ also have dual roles in adhesion and signaling and whether homophilic interactions mediated by this family of proteins contributes to additional signaling events. 


\section{MATERIALS AND METHODS}

\section{Antibodies}

Antibodies and dilutions used were mouse anti-Dally-like (DIp) antibody 1:50 (DSHB, 13G8); mouse anti-Ptc antibody 1:50 (DSHB, Apa1); mouse anti- $\alpha$-tubulin (DM1A, EMD Millipore) 1:5000; mouse anti-HA 1:1000 (HA.11, Covance); mouse anti- $\beta$-tubulin 1:5000 (DSHB, E7); rabbit anti-GFP 1:1000 (Invitrogen, A-11122); rat anti-Ihog antibody 1:500 (Yao et al. 2006); rabbit anti-Hh at 1:500 (Tabata and Kornberg 1994). HRP-conjugated and Fluorophoreconjugated secondary antibodies were from Jackson Immuno-Research Lab. Alexa Fluor® 594 Phalloidin was from Thermo Fischer. The antibody information is also listed in the key resources table (Supplementary Table 1).

\section{Cell culture and transfection}

Drosophila S2 cells (DGRC) were cultured in Drosophila Schneider's medium supplemented with $10 \%$ of fetal bovine serum (Omega Scientific) and 1\% Penicillin-Streptomycin-Glutamine (Thermo Fisher) at $25^{\circ} \mathrm{C}$ in a humidified incubator. Transfection was performed with FuGENE 6 transfection reagent (Promega). Expression constructs of GFP, mCherry, HhN, Hh, Ihog and Ihog-YFP used in Drosophila cell culture were cloned into pAcSV plasmid as previously described (Wu et al. 2019).

\section{Cell aggregation assay}

S2 cells were transfected separately with plasmids expressing desired proteins. 48 hours after transfection, S2 cells were washed with PBS and dissociated by $0.05 \%$ trypsin treatment for 5 $\min$ at $25^{\circ} \mathrm{C}$. The dissociated cells were resuspended in fresh medium with $10 \%$ fetal bovine serum. The resuspended cells were then incubated in $1.5 \mathrm{ml}$ ultra-low adhesion microcentrifuge 
tubes with gentle rotation at room temperature for the time indicated in the figure legends. Cells were then transferred into glass bottom dishes (D35-20-1.5-N, In Vitro Scientific) for live imaging by microscopy. In the experiments involving mixing differentially labeled red and green cells, cells co-expressing GFP or mCherry with the plasmid expressing the protein of interest were counted under microscope and mixed with equal number of transfected cells prior to incubation with rotation.

To assess cell aggregation, low-magnification fields of similar cell density were randomly taken from each cell aggregation experiment, and the cell clusters were scored if they contained three or more cells. The aggregation effect was quantified as the ratio of certain transfected cells within clusters to total transfected cells (both clustered and non-clustered). Each bar shows the mean \pm SD from 20-30 different images. Unpaired two-tailed t test was used for statistical analysis. Statistical analysis was performed using GraphPad Prism software.

\section{Cell immunostaining and imaging}

48 hours after transfection, dissociated S2 cells were allowed to settle and adhere for 60 min on a glass coverslip. Cells were then washed twice with PBS, fixed in $4 \%$ formaldehyde (Electron Microscopy Sciences) in PBS, blocked and permeabilized by $1.5 \%$ normal goat serum (NGS) \& $0.1 \%$ Triton $\mathrm{X}-100$ in PBS, incubated with primary antibody in PBS containing $1.5 \%$ NGS and $0.1 \%$ Triton $\mathrm{X}-100$ for $1 \mathrm{hr}$ at room temperature, washed 3 times with $0.1 \%$ Triton $\mathrm{X}-100 / \mathrm{PBS}$, incubated with secondary antibody (with or without Phalloidin) and washed with $0.1 \%$ Triton X100/PBS. The stained cells were mounted using the Vectashield anti-fade mounting medium $(H-$ 1000) and imaged with a Zeiss spinning disc confocal microscope.

\section{Computational model of cytonemes}

We simulated the cytonemes using a in silico stochastic assay. The cell surface is simplified as a linear base line with length $M$ (shown as the black solid lines in the bottom of Fig. $5 \mathrm{~A}$ ). In the 
initial step, we randomly picked $30 \% \times M$ locations along the base line as the initial locations for the cytonemes. The initial cytoneme lengths are all 0.

In each simulation step, the binary interaction variable $S_{k}^{i j}$ was randomly assigned for each pair of neighboring segments according to Eq. 3. From $S_{k}^{i j}$, the number of tip interactions for each cytoneme $\left(T_{i}\right)$ and the total homophilic trans interaction for the $i^{\text {th }}$ cytoneme $\left(E_{\text {interaction }}^{i}\right)$ can be obtained. For each cytoneme, its probabilities of elongation and shrinkage (i.e. $p_{\text {elongation }}$ and $p_{\text {shrinkage }}$ ) were computed using equations $1 \& 2$; a random number $r \in$ $[0,1]$ was picked; if the cytoneme length was larger than 0 and $r \leq p_{\text {shrinkage }} /\left(p_{\text {elongation }}+\right.$ $\left.p_{\text {shrinkage }}\right)$, the cytoneme length was shrunk by 1 segment; otherwise it was elongated by 1 . Once all cytonemes were elongated/shrunk, 1 cytoneme was randomly picked and tentatively moved along the cell surface base line; the interaction variables $S_{k}^{i j *}$ were re-assigned based this tentative configuration and the energy change $\Delta E_{\text {translocation }}^{i}$ was calculated; another random number $r \in[0,1]$ was picked and the tentative move would be accepted if and only if $r \leq \min \left(1, \exp \left(-\Delta E_{\text {translocation }}^{i} / k_{B} T\right)\right)$.

For each choice of $E_{i i}$, we allow the cytoneme system to evolve for more than $5,000,000$ steps. Data were collected after 1,000,000 simulation steps when the cytoneme system reached steady state. In our showed results, we set $M=100, p_{\text {elongation }}^{0}=5, p_{\text {shrinage }}^{0}=0.5$ and $\alpha=$ 0.2. We tested different parameters and the general conclusions remained the same.

The cytoneme bundles were identified as a collection of parallel cytonemes located close together and forming more than 3 pairwise contacts between two cytonemes. The cytoneme bundling index is calculated by multiplying the minimum cytoneme length by the cytoneme number within each bundle.

\section{Computational modeling of cell rearrangement}


We modeled the Ihog-Ihog and Ihog-Hh interactions using a vertex-based in silico assay (Bi et al. 2015; Park et al. 2016). Based on mechanical free energy calculated according to Eq. 5, we used the Metropolis Monte Carlo method to perform the simulations. Simulations were performed within a $L \times L 2$-D square space with a periodic boundary condition along the $x$ - and y- axes. The initial conditions were sets of randomly generated morphologies: We first assigned $N$ cellular points and $5 \times N$ environmental points randomly distributed in the 2-D space, then used the Voronoi tessellation function in MatLab to partition the space into $6 \times N$ polygons based on these points, representing the $N$ cells and the empty space surrounding them.

We implemented Metropolis Monte Carlo simulations by moving the $6 \times N$ points according to the mechanical energy: In each tentative move, a random point is selected and a random displacement $\Delta \boldsymbol{l}$ is assigned to it; the moved point causes re-partitioning of the 2-D monolayer using the Voronoi tessellation function, which results in a change in the monolayer's mechanical energy, $\Delta U^{\prime}$; a random number $r \in[0,1]$ is picked and the tentative move will be accepted if and only if $r \leq \min \left(1, \exp \left(-\Delta U^{\prime} / k_{B} T\right)\right)$.

We allowed the monolayer to randomly evolve for more than 650,000 steps. To ensure simulation efficiency, we adjusted the maximum allowed displacement to maintain the overall accept rate to be around $25 \sim 40 \%$. Data were collected after 200,000 simulation steps when the monolayer's morphology had reached steady state.

In our simulations, $L$ is set to 20 , and both the Hh-expressing $S 2$ cells and the Ihogexpressing S2 cells are set with a unit area $A_{0}=1$. For simplicity, we assumed that areal elastic coefficient $\alpha=500$ and the contractile coefficient $\beta=6$ are the same for different types of cells. To account for the differential cell-cell adhesion, $\gamma_{H H}$ was set to 0 (Hh-expressing cells do not aggregate), $\gamma_{I I}=0.25$ for interaction between lhog-expressing cells, we modulated the ratio $\gamma_{I H}: \gamma_{I I}$ to set $\gamma_{I H}$ for our parameter study. 


\section{Drosophila strains}

The ptc-GAL4 (Hinz et al. 1994) driver and tub-Gal80 (McGuire et al. 2003) were used for transient expression of transgenic constructs using the GAL4/UAS system (Brand and Perrimon 1993). Fly crosses were maintained at $18^{\circ} \mathrm{C}$, and the Gal80 $0^{t s}$ repressor was inactivated for $24 \mathrm{hr}$ at restrictive temperature $\left(29^{\circ} \mathrm{C}\right)$ before dissection. The actin $>y+>G A L 4$ (Ito et al. 1997) driver was used to generate random ectopic clones of the UAS lines. The CoinFLP-LexA::GAD.GAL4 driver was used to generate random clones expressing either UAS-CD4-spGFP1-10 or lexAopCD4-spGFP11 (Feinberg et al. 2008; Gordon and Scott 2009; Bosch et al. 2015). Larvae of the corresponding genotypes were incubated at $37^{\circ} \mathrm{C}$ for $30-60$ min to induce $h s-F L P$-mediated recombinant clones. The genotypes (see DETAILED GENOTYPES) of larvae for transient or random expression of transgenic constructs are listed in the key resources table (Supplementary Table 1).

\section{Imaginal discs immunostaining and imaging}

Wing discs from $3^{\text {rd }}$ instar larvae were dissected, fixed in $4 \%$ formaldehyde (Electron Microscopy Sciences) in PBS, blocked and permeabilized by $5 \%$ normal goat serum (NGS) \& $0.3 \%$ Triton X-100 in PBS, incubated with primary antibody in PBS containing 5\% NGS and $0.3 \%$ Triton $\mathrm{X}-100$ overnight at $4^{\circ} \mathrm{C}$, washed 3 times with $0.3 \%$ Triton $\mathrm{X}-100 / \mathrm{PBS}$, incubated with secondary antibody, and washed with $0.3 \%$ Triton X-100/PBS. The stained discs were mounted and imaged with a ZEISS spinning disc confocal microscope or a ZEISS LSM 880 with Airyscan. Average cytoneme length was determined using ImageJ and plotted using GraphPad Prism software.

\section{MBP-HhN purification}

The MBP-HhN expression plasmid was a gift from Dr. Daniel Leahy (The University of Texas at Austin). A DNA fragment encoding the Drosophila melanogaster Hh residues $85-248(\mathrm{HhN})$ 
was cloned into the MBP-HTSHP expression vector, which was modified based on the pMal-c2x vector (New England Biolabs) by including a linker region with various tags (His-TEV-Strep-HisPreScission). Similar to the procedure described previously (8), the fusion proteins were expressed in Escherichia coli strain B834 (DE3) by induction with $1 \mathrm{mM}$ isopropyl 1-thio- $\beta$-Dgalactopyranoside overnight at $16^{\circ} \mathrm{C}$. Cells were harvested, lysed, and centrifuged, and the supernatant was passed over nickel-nitrilotriacetic acid resin (Qiagen). Proteins were eluted with imidazole according to the manufacturer's suggestions. The elution was then placed into $6000-$ 8000 molecular weight-cutoff 40-mm dialysis tubing and dialyzed against $20 \mathrm{mM}$ Tris (pH 8.0) and $200 \mathrm{mM} \mathrm{NaCl}$.

\section{Western blot analysis}

48 hours after transfection, S2 cells were lysed in 1\% NP40 (50 mM Tris- $\mathrm{HCl}$ at pH 6.8, $150 \mathrm{mM}$ $\mathrm{NaCl}$, and protease inhibitors) for $30 \mathrm{~min}$ at room temperature. The lysate was clarified by centrifugation, and proteins were recovered directly in SDS-PAGE sample buffer. Proteins were separated by SDS-PAGE under reducing conditions and then transferred onto PVDF membranes (Millipore). After protein transfer, the membranes were blocked and then immunostained with primary antibodies and HRP-conjugated secondary antibodies.

\section{Statistical analysis}

All data in column graphs are shown as mean values with SD and plotted using GraphPad Prism software. Statistical analyses were performed with unpaired two-tailed t-test, one-way ANOVA followed by Dunnett's, Sidak's or Tukey's multiple comparisons test, or two-sided Fisher's exact test was used for statistical analysis as described in the figure legends. The sample sizes were set based on the variability of each assay and are listed in the Figure legends. Independent experiments were performed as indicated to guarantee reproducibility of findings. Differences were considered statistically significant when $P<0.01$. 


\section{ACKNOWLEDGMENTS}

We thank S. Blair, I. Guerrero, D. Leahy, T. Tabata, the Bloomington Drosophila Stock Center, the Vienna Drosophila RNAi Center, Kyoto Stock Center and the Developmental Studies

Hybridoma Bank for fly strains and reagents. We thank A. Popratiloff from the GW

Nanofabrication \& Imaging Center, members of the Anatomy and Cell Biology Department for comments during the development of this work. We thank N. R. Gough for helpful discussions.

\section{FUNDING:}

This work is supported by NIH (R01GM117440), GW Cancer Center, and Clinical \& Translational Science Institute at Children's National Hospital.

\section{AUTHOR CONTRIBUTIONS}

X.Z. and G.L. conceived of the presented idea. S.Y., Y.Z, X. W., X.S.W., R.C and X.C. carried out the experiments. G.L., C.Y, and S.O. developed the theory and performed the computations. All authors discussed the results and contributed to the final manuscript.

\section{CONFLICT OF INTEREST STATEMENT}

The authors declare that they have no conflicts of interest with the contents of this article. 


\section{REFERENCE}

Ayers KL, Gallet A, Staccini-Lavenant L, Therond PP. 2010. The Long-Range Activity of Hedgehog Is Regulated in the Apical Extracellular Space by the Glypican Dally and the Hydrolase Notum. Developmental Cell 18: 605-620.

Basler K, Struhl G. 1994. Compartment boundaries and the control of Drosophila limb pattern by hedgehog protein. Nature 368: 208-214.

Bernfield M, Gotte M, Park PW, Reizes O, Fitzgerald ML, Lincecum J, Zako M. 1999. Functions of cell surface heparan sulfate proteoglycans. Annu Rev Biochem 68: 729-777.

Bi DP, Lopez JH, Schwarz JM, Manning ML. 2015. A density-independent rigidity transition in biological tissues. Nat Phys 11: 1074-+.

Bilioni A, Sánchez-Hernández D, Callejo A, Gradilla A-CC, Ibáñez C, Mollica E, Carmen Rodríguez-Navas M, Simon E, Guerrero I. 2013. Balancing Hedgehog, a retention and release equilibrium given by Dally, Ihog, Boi and shifted/DmWif. Developmental biology 376: 198-212.

Bischoff M, Gradilla AC, Seijo I, Andres G, Rodriguez-Navas C, Gonzalez-Mendez L, Guerrero I. 2013. Cytonemes are required for the establishment of a normal Hedgehog morphogen gradient in Drosophila epithelia. Nat Cell Biol 15: 1269-1281.

Bodeen WJ, Marada S, Truong A, Ogden SK. 2017. A fixation method to preserve cultured cell cytonemes facilitates mechanistic interrogation of morphogen transport. Development 144: 3612-3624.

Bosch JA, Tran NH, Hariharan IK. 2015. CoinFLP: a system for efficient mosaic screening and for visualizing clonal boundaries in Drosophila. Development 142: 597-606.

Brand AH, Perrimon N. 1993. Targeted Gene-Expression as a Means of Altering Cell Fates and Generating Dominant Phenotypes. Development 118: 401-415.

Callejo A, Bilioni A, Mollica E, Gorfinkiel N, Andres G, Ibanez C, Torroja C, Doglio L, Sierra J, Guerrero I. 2011. Dispatched mediates Hedgehog basolateral release to form the longrange morphogenetic gradient in the Drosophila wing disk epithelium. Proc Natl Acad Sci U S A 108: 12591-12598.

Camp D, Currie K, Labbe A, van Meyel DJ, Charron F. 2010. Ihog and Boi are essential for Hedgehog signaling in Drosophila. Neural development 5: 28.

Capdevila J, Estrada MP, Sanchez-Herrero E, Guerrero I. 1994. The Drosophila segment polarity gene patched interacts with decapentaplegic in wing development. Embo $\mathrm{J} 13$ : 71-82.

Chen W, Huang H, Hatori R, Kornberg TB. 2017. Essential basal cytonemes take up Hedgehog in the Drosophila wing imaginal disc. Development 144: 3134-3144.

Chen Y, Struhl G. 1996. Dual roles for patched in sequestering and transducing Hedgehog. Cell 87: 553-563.

Chou YH, Zheng X, Beachy PA, Luo L. 2010. Patterning axon targeting of olfactory receptor neurons by coupled hedgehog signaling at two distinct steps. Cell 142: 954-966.

Eaton S, Kornberg TB. 1990. Repression of ci-D in posterior compartments of Drosophila by engrailed. Genes Dev 4: 1068-1077.

Eugster C, Panakova D, Mahmoud A, Eaton S. 2007. Lipoprotein-heparan sulfate interactions in the Hh pathway. Dev Cell 13: 57-71.

Farhadifar R, Roper JC, Aigouy B, Eaton S, Julicher F. 2007. The influence of cell mechanics, cell-cell interactions, and proliferation on epithelial packing. Current biology : CB 17: 2095-2104.

Feinberg EH, Vanhoven MK, Bendesky A, Wang G, Fetter RD, Shen K, Bargmann Cl. 2008. GFP Reconstitution Across Synaptic Partners (GRASP) defines cell contacts and synapses in living nervous systems. Neuron 57: 353-363. 
Foty RA, Steinberg MS. 2005. The differential adhesion hypothesis: a direct evaluation. Dev Biol 278: $255-263$.

Frei T, von Bohlen und Halbach F, Wille W, Schachner M. 1992. Different extracellular domains of the neural cell adhesion molecule (N-CAM) are involved in different functions. $J$ Cell Biol 118: 177-194.

Fujise M, Izumi S, Selleck SB, Nakato H. 2001. Regulation of dally, an integral membrane proteoglycan, and its function during adult sensory organ formation of Drosophila. Developmental Biology 235: 433-448.

Fujise M, Takeo S, Kamimura K, Matsuo T, Aigaki T, Izumi S, Nakato H. 2003. Dally regulates Dpp morphogen gradient formation in the Drosophila wing. Development 130: 15151522.

Garcia-Bellido A, Ripoll P, Morata G. 1973. Developmental compartmentalisation of the wing disk of Drosophila. Nature: New biology 245: 251-253.

Gibson MC, Patel AB, Nagpal R, Perrimon N. 2006. The emergence of geometric order in proliferating metazoan epithelia. Nature 442: 1038-1041.

Gonzalez-Mendez L, Gradilla AC, Guerrero I. 2019. The cytoneme connection: direct longdistance signal transfer during development. Development 146.

Gonzalez-Mendez L, Gradilla AC, Sanchez-Hernandez D, Gonzalez E, Aguirre-Tamaral A, Jimenez-Jimenez C, Guerra M, Aguilar G, Andres G, Falcon-Perez JM et al. 2020. Polarized sorting of Patched enables cytoneme-mediated Hedgehog reception in the Drosophila wing disc. Embo J 39: e103629.

Gonzalez-Mendez L, Seijo-Barandiaran I, Guerrero I. 2017. Cytoneme-mediated cell-cell contacts for Hedgehog reception. Elife 6.

Gordon MD, Scott K. 2009. Motor control in a Drosophila taste circuit. Neuron 61: 373-384.

Goutsias J. 2005. Quasiequilibrium approximation of fast reaction kinetics in stochastic biochemical systems. The Journal of chemical physics 122: 184102.

Gradilla AC, Gonzalez E, Seijo I, Andres G, Bischoff M, Gonzalez-Mendez L, Sanchez V, Callejo A, Ibanez C, Guerra M et al. 2014. Exosomes as Hedgehog carriers in cytoneme-mediated transport and secretion. Nature communications $\mathbf{5}$.

Gradilla AC, Guerrero I. 2013. Hedgehog on the move: a precise spatial control of Hedgehog dispersion shapes the gradient. Curr Opin Genet Dev 23: 363-373.

Greco V, Hannus M, Eaton S. 2001. Argosomes: A potential vehicle for the spread of morphogens through epithelia. Cell 106: 633-645.

Hall ET, Stewart DP, Dillard M, Wagner B, Sykes A, Temirov J, Cheney RE, Mori M, Robinson CG, Ogden SK. 2020. Myosin 10 and a Cytoneme-Localized Ligand Complex Promote Morphogen Transport. bioRxiv: 2020.2005.2006.080820.

Han C, Yan D, Belenkaya TY, Lin XJ. 2005. Drosophila glypicans Dally and Dally-like shape the extracellular Wingless morphogen gradient in the wing disc. Development 132: 667-679.

Hartman TR, Zinshteyn D, Schofield HK, Nicolas E, Okada A, O'Reilly AM. 2010. Drosophila Boi limits Hedgehog levels to suppress follicle stem cell proliferation. J Cell Biol 191: 943952.

Hinz U, Giebel B, Campos-Ortega JA. 1994. The basic-helix-loop-helix domain of Drosophila lethal of scute protein is sufficient for proneural function and activates neurogenic genes. Cell 76: 77-87.

Honda H, Yamanaka H, Eguchi G. 1986. Transformation of a polygonal cellular pattern during sexual maturation of the avian oviduct epithelium: computer simulation. Journal of embryology and experimental morphology 98: 1-19.

Hsia EYC, Zhang Y, Tran HS, Lim A, Chou YH, Lan G, Beachy PA, Zheng X. 2017. Hedgehog mediated degradation of Ihog adhesion proteins modulates cell segregation in Drosophila wing imaginal discs. Nature communications 8: 1275. 
Huff J. 2015. The Airyscan detector from ZEISS: confocal imaging with improved signal-to-noise ratio and super-resolution. Nature Methods 12.

Ingham PW, Taylor AM, Nakano Y. 1991. Role of the Drosophila patched gene in positional signalling. Nature 353: 184-187.

Ito K, Awano W, Suzuki K, Hiromi Y, Yamamoto D. 1997. The Drosophila mushroom body is a quadruple structure of clonal units each of which contains a virtually identical set of neurones and glial cells. Development 124: 761-771.

Juliano RL. 2002. Signal transduction by cell adhesion receptors and the cytoskeleton: functions of integrins, cadherins, selectins, and immunoglobulin-superfamily members. Annual review of pharmacology and toxicology 42: 283-323.

Kornberg TB. 2014. Cytonemes and the dispersion of morphogens. Wiley interdisciplinary reviews Developmental biology 3: 445-463.

Lin X. 2004. Functions of heparan sulfate proteoglycans in cell signaling during development. Development 131: 6009-6021.

Lum L, Yao S, Mozer B, Rovescalli A, Von Kessler D, Nirenberg M, Beachy PA. 2003. Identification of Hedgehog pathway components by RNAi in Drosophila cultured cells. Science 299: 2039-2045.

Mann RK, Beachy PA. 2004. Novel lipid modifications of secreted protein signals. in Annu Rev Biochem, pp. 891-923.

Martin-Bermudo MD, Brown NH. 1999. Uncoupling integrin adhesion and signaling: the betaPS cytoplasmic domain is sufficient to regulate gene expression in the Drosophila embryo. Genes Dev 13: 729-739.

Mattila PK, Lappalainen P. 2008. Filopodia: molecular architecture and cellular functions. Nat Rev Mol Cell Biol 9: 446-454.

McGuire SE, Le PT, Osborn AJ, Matsumoto K, Davis RL. 2003. Spatiotemporal rescue of memory dysfunction in Drosophila. Science 302: 1765-1768.

McLellan JS, Yao S, Zheng X, Geisbrecht BV, Ghirlando R, Beachy PA, Leahy DJ. 2006. Structure of a heparin-dependent complex of Hedgehog and Ihog. Proc Natl Acad Sci U S A 103: 17208-17213.

Metropolis. 1953. Equation of State Calculations by Fast Computing Machines. he Journal of Chemical Physics 21.

Muenke M, Beachy PA. 2000. Genetics of ventral forebrain development and holoprosencephaly. Current opinion in genetics \& development 10: 262-269.

Mullor JL, Calleja M, Capdevila J, Guerrero I. 1997. Hedgehog activity, independent of decapentaplegic, participates in wing disc patterning. Development 124: 1227-1237.

Orian-Rousseau V, Ponta H. 2008. Adhesion proteins meet receptors: a common theme? Advances in cancer research 101: 63-92.

Park H, Heldman N, Rebentrost P, Abbondanza L, lagatti A, Alessi A, Patrizi B, Salvalaggio M, Bussotti L, Mohseni M et al. 2016. Enhanced energy transport in genetically engineered excitonic networks. Nature materials 15: 211-216.

Portela M, Venkataramani V, Fahey-Lozano N, Seco E, Losada-Perez M, Winkler F, CasasTinto S. 2019. Glioblastoma cells vampirize WNT from neurons and trigger a JNK/MMP signaling loop that enhances glioblastoma progression and neurodegeneration. PLoS Biol 17: e3000545.

Ramirez-Weber FA, Kornberg TB. 1999. Cytonemes: cellular processes that project to the principal signaling center in Drosophila imaginal discs. Cell 97: 599-607.

Rojas-Rios P, Guerrero I, Gonzalez-Reyes A. 2012. Cytoneme-mediated delivery of hedgehog regulates the expression of bone morphogenetic proteins to maintain germline stem cells in Drosophila. PLoS Biol 10: e1001298.

Roy S, Hsiung F, Kornberg TB. 2011. Specificity of Drosophila cytonemes for distinct signaling pathways. Science 332: 354-358. 
Sanders TA, Llagostera E, Barna M. 2013. Specialized filopodia direct long-range transport of SHH during vertebrate tissue patterning. Nature 497: 628-632.

Sjostrand D, Carlsson J, Paratcha G, Persson B, Ibanez CF. 2007. Disruption of the GDNF binding site in NCAM dissociates ligand binding and homophilic cell adhesion. $J$ Biol Chem 282: 12734-12740.

Steinberg MS. 2007. Differential adhesion in morphogenesis: a modern view. Curr Opin Genet Dev 17: 281-286.

Strigini M, Cohen SM. 1997. A Hedgehog activity gradient contributes to AP axial patterning of the Drosophila wing. Development 124: 4697-4705.

Tabata T, Kornberg TB. 1994. Hedgehog is a signaling protein with a key role in patterning Drosophila imaginal discs. Cell 76: 89-102.

Tabata T, Takei Y. 2004. Morphogens, their identification and regulation. Development 131: 703-712.

Varjosalo M, Taipale J. 2008. Hedgehog: functions and mechanisms. Genes \& development 22: 2454-2472.

Wu X, Zhang Y, Chuang KH, Cai X, Ajaz H, Zheng X. 2019. The Drosophila Hedgehog receptor component Interference hedgehog (Ihog) mediates cell-cell interactions through transhomophilic binding. J Biol Chem 294: 12339-12348.

Yan D, Wu Y, Yang Y, Belenkaya TY, Tang X, Lin X. 2010. The cell-surface proteins Dally-like and Ihog differentially regulate Hedgehog signaling strength and range during development. Development 137: 2033-2044.

Yao S, Lum L, Beachy P. 2006. The ihog cell-surface proteins bind Hedgehog and mediate pathway activation. Cell 125: 343-357.

Zecca M, Basler K, Struhl G. 1995. Sequential organizing activities of engrailed, hedgehog and decapentaplegic in the Drosophila wing. Development 121: 2265-2278.

Zhang FM, McLellan JS, Ayala AM, Leahy DJ, Linhardt RJ. 2007. Kinetic and structural studies on interactions between heparin or heparan sulfate and proteins of the hedgehog signaling pathway. Biochemistry-Us 46: 3933-3941.

Zheng X, Mann RK, Sever N, Beachy PA. 2010. Genetic and biochemical definition of the Hedgehog receptor. Genes Dev 24: 57-71. 


\section{Yang_Figure 1}

A
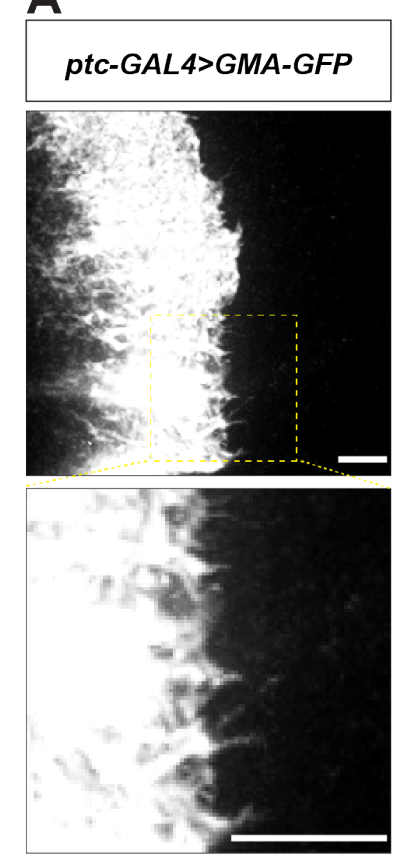
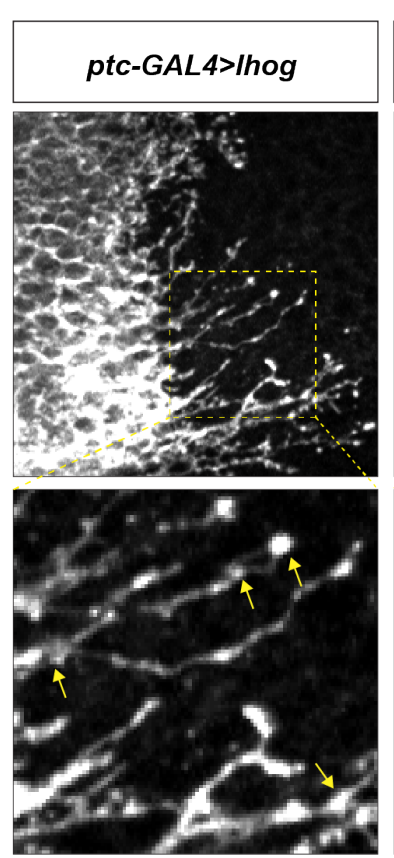
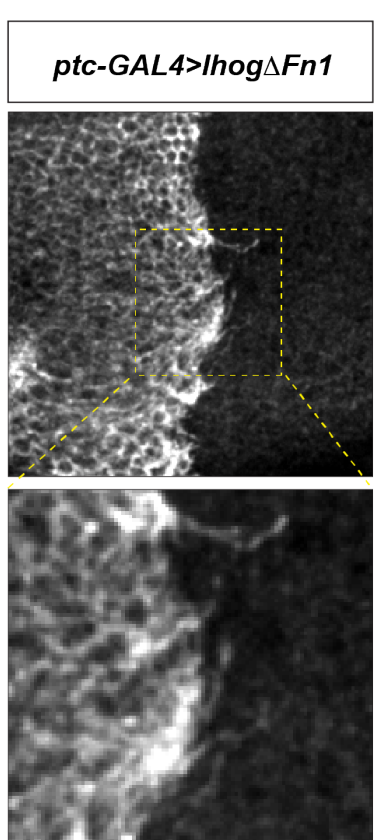

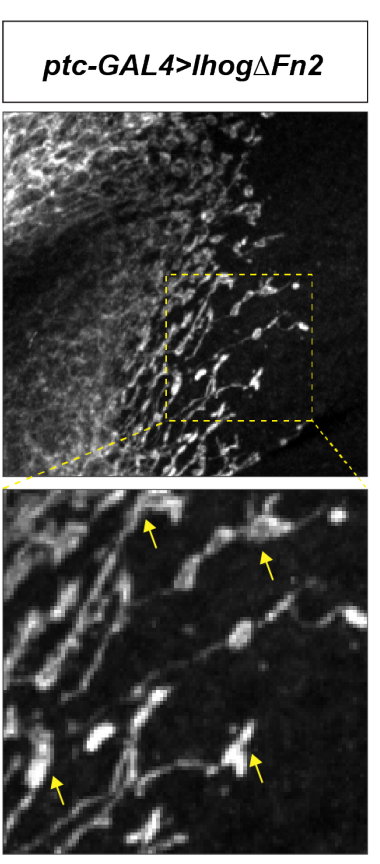

B

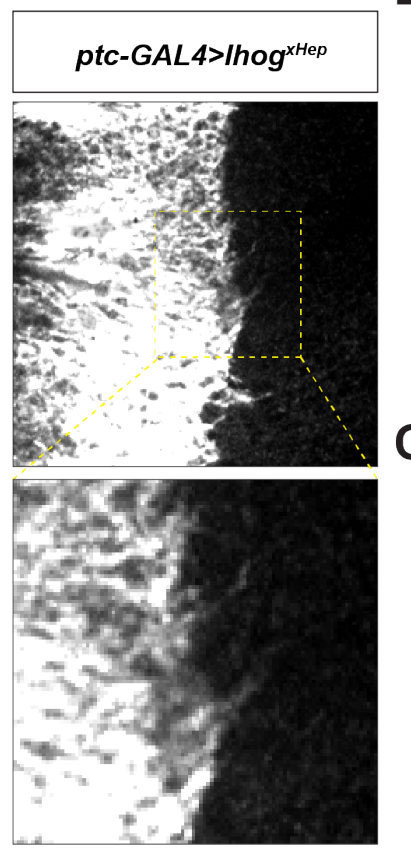

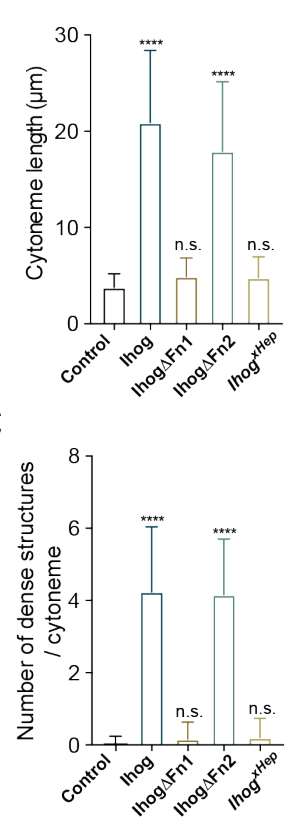

Figure 1. Ihog mediates cytoneme stabilization via the Fn1 domain

(A) Wing discs from $3^{\text {rd }}$ instar larvae carrying ptc-GAL4, tub-GAL8O $0^{t s}$ and the indicated UAS-transgenes were immunostained for GFP or Ihog to visualize cytonemes projecting from Hh-receiving cells. Yellow arrows indicate the dense structures along the cytonemes. Scale bar, $10 \mu \mathrm{m}$. (B, C) Quantification of the average cytoneme length (B) and the average dense structures number per cytoneme (C) in the wing disc. Each bar shows the mean \pm SD $(n>30)$. One-way ANOVA followed by Dunnett's multiple comparison test was used for statistical analysis. ns, not significant. ${ }^{* * * P}<0.0001$. 


\section{Yang_Figure 2}

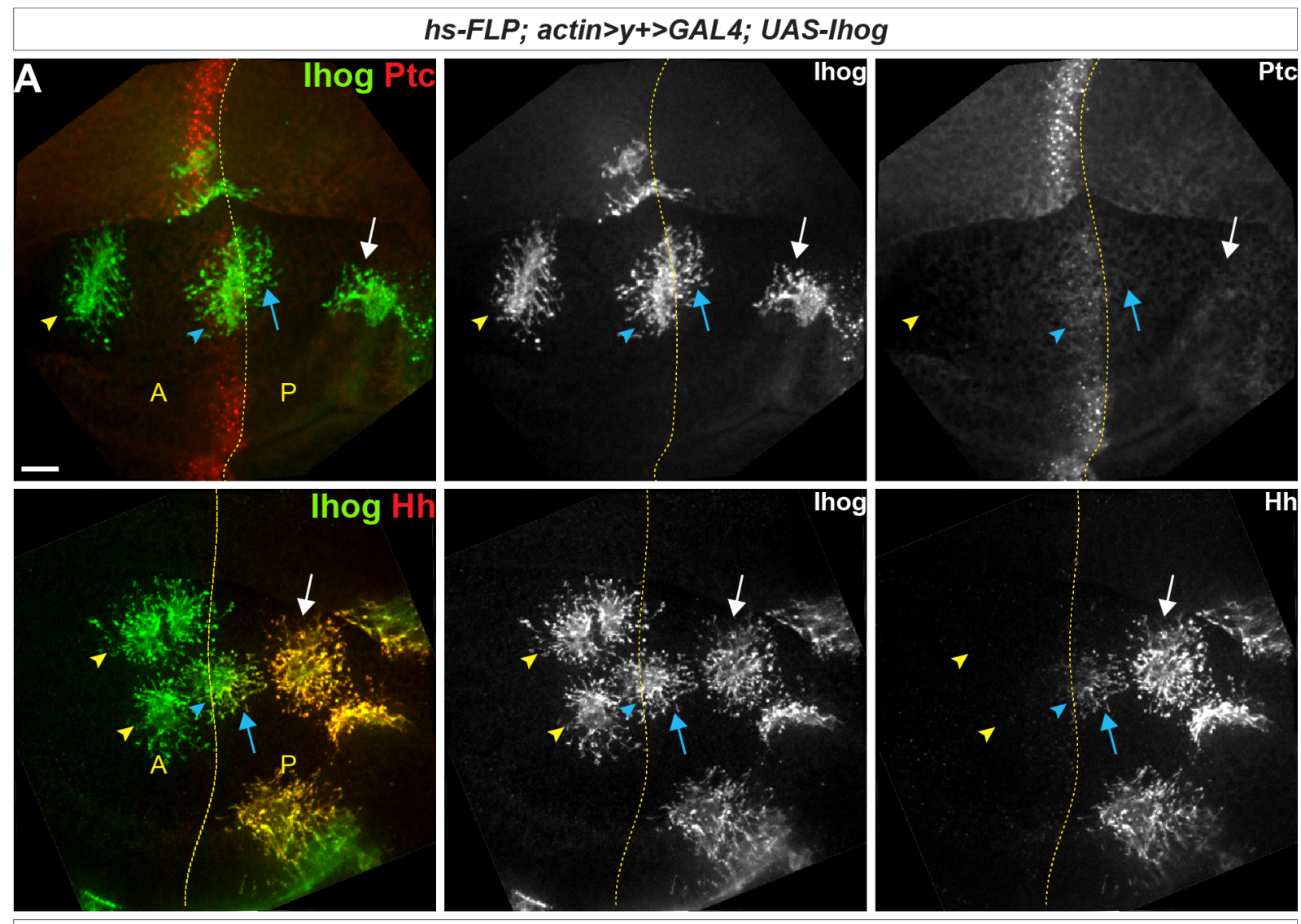

hs-FLP; actin>y+>GAL4; UAS-Ihog $\Delta F n 2$
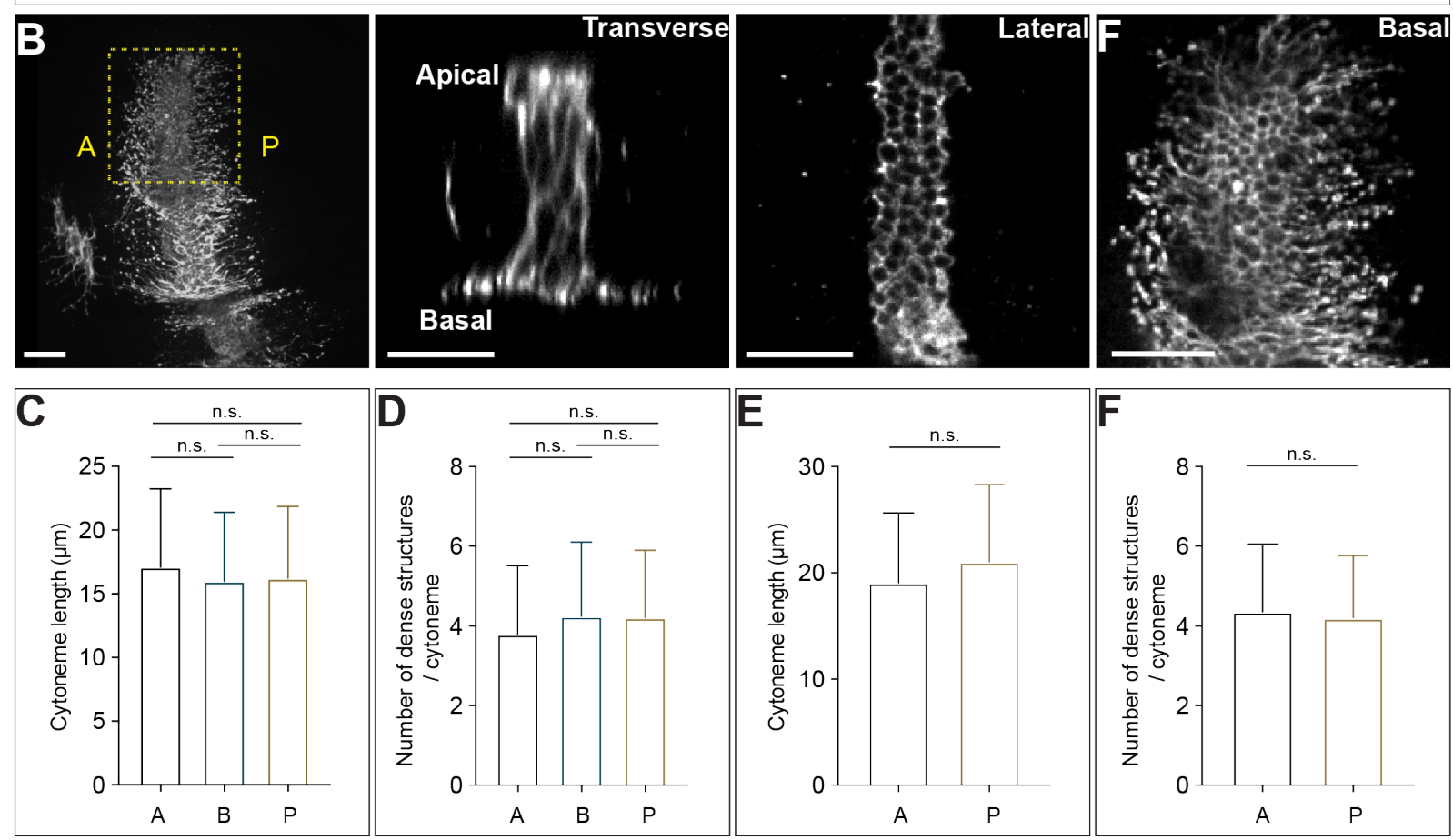


\section{Yang_Figure 2}

Figure 2. Ihog mediates cytoneme stabilization in a manner independent of the Hh receptor function

(A) Wing discs from $3^{\text {rd }}$ instar larvae carrying flip-out clones expressing UAS-Ihog were immunostained for lhog (green) and Ptc or Hh (red) as indicated. Dashed yellow line indicate the A/P compartment boundary; white arrows indicate clones located within the P compartment; blue arrows indicate cytonemes of clones located at the A/P boundary that project toward the Hh producing cells; blue arrowheads indicate cytonemes of clones located at the A/P boundary that project away from the Hh producing cells; yellow arrowheads indicate cytonemes from clones located within the A compartment. Scale bar, $20 \mu \mathrm{m}$. (B) Flip-out clones expressing UASIhog $\Delta F n 2$ viewed from the basal side at low magnification and in transverse, lateral, and basal sections of the same clone, showing localization of Ihog $\Delta \mathrm{Fn} 2$ proteins at the apical-lateral/lateral cell-cell contacts and basal cytonemes. Scale bar, $20 \mu \mathrm{m}$. (C, D) Quantification of the average cytoneme length and the average dense structure number per cytoneme for $A$ (clones located in the Ptc ${ }^{\text {low }}$ A compartment), B (Ptc ${ }^{\text {high }} A / P$ compartment boundary), and P (Ptc ${ }^{\text {neg }} P$ compartment). (E, F) Quantification of the average cytoneme length and the average dense structure number per cytoneme for A (cytonemes projecting anteriorly away from the Hh source) and $\mathrm{P}$ (cytonemes projecting posteriorly towards the source of $\mathrm{Hh}$ ). Each bar shows the mean \pm SD $(n=30)$. One-way ANOVA followed by Tukey's multiple comparison test $(C, D)$ or the twotailed unpaired t-test (E, F) was used for statistical analysis. ns, not significant. 


\section{Yang_Figure 3}

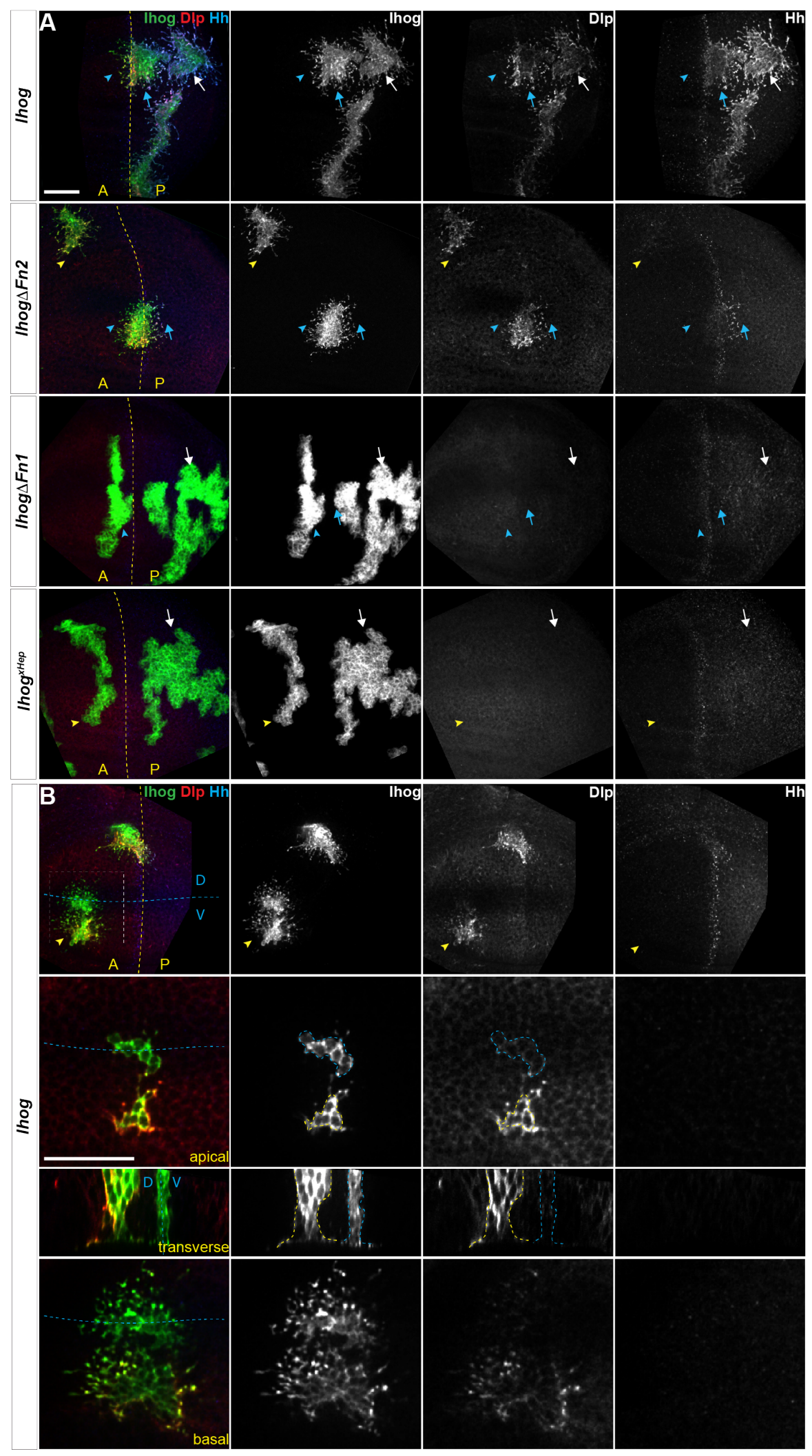




\section{Yang_Figure 3}

Figure 3. Ectopic Ihog induces accumulation of glypicans at lateral cell-cell contacts and along basal cytonemes

Wing discs from $3^{\text {rd }}$ instar larvae carrying flip-out clones expressing the indicated UAStransgene were immunostained for Ihog (green), Dlp (red), and Hh (blue). Dashed yellow lines indicate the A/P compartment boundary; dashed blue lines indicates the dorsal/ventral (D/V) compartment boundary. (A) lhog or lhog mutants were expressed in wing discs. White arrows indicate clones located within the P compartment; blue arrows indicate cytonemes of clones located at the A/P boundary that project toward the Hh producing cells; blue arrowheads indicate cytonemes of clones located at the A/P boundary that project away from the Hh producing cells; yellow arrowheads indicate cytonemes from clones located within the A compartment. (B) Flip-out clones expressing UAS-Ihog viewed from the basal side at low magnification and in lateral, transverse, and basal sections of the zoomed area. The upper row shows the imaged clones (outlined with dashed white lines) with their position relative to the A/P and D/V boundaries. Blue outline indicates the flip-out clone flanking the D/N boundary; the yellow outline indicates the clone several cell diameters away from the D/V boundary. Scale bar, $20 \mu \mathrm{m}$. 


\section{Yang_Figure 4}

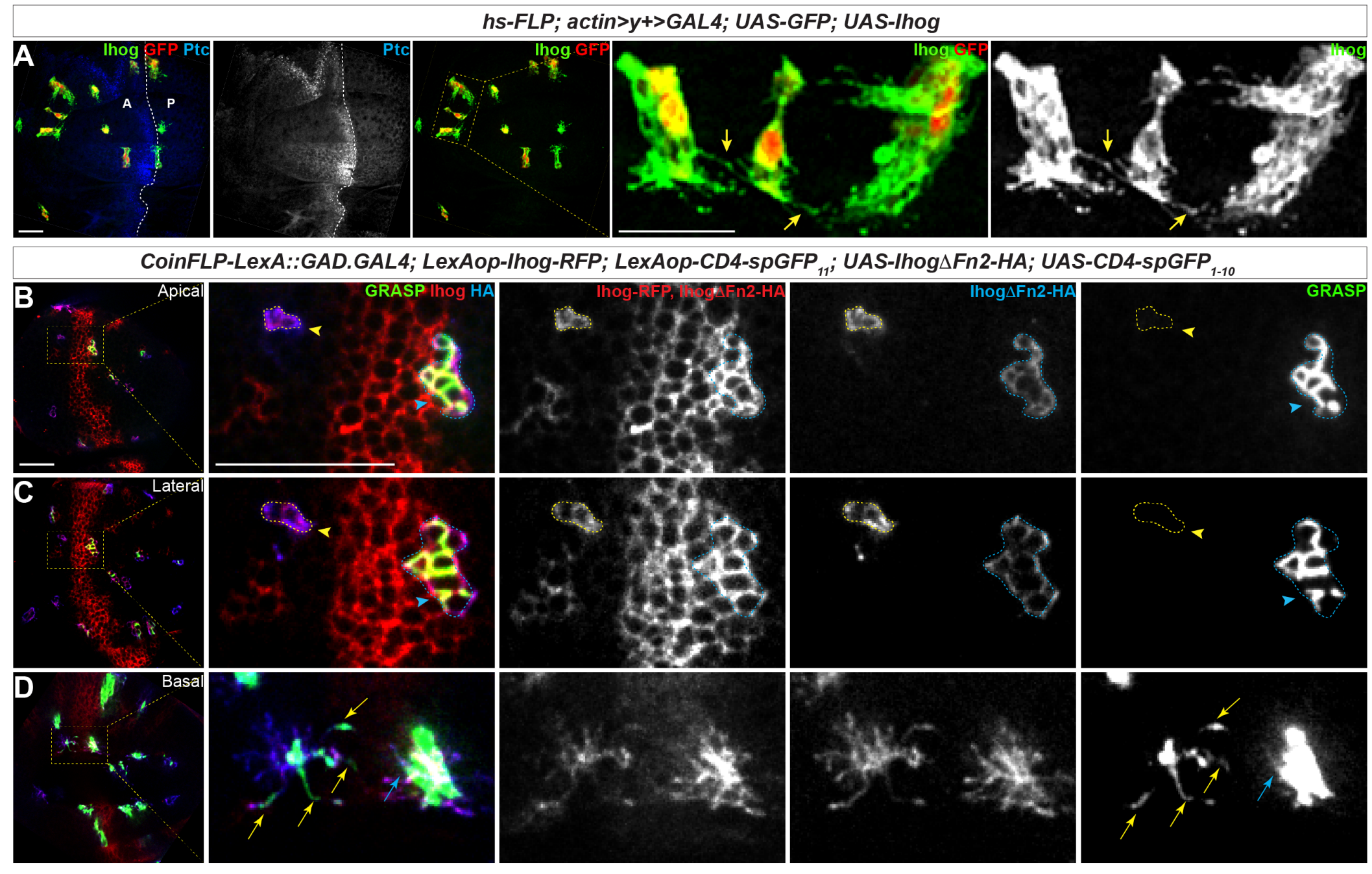




\section{Yang_Figure 4}

Figure 4. Homophilic lhog trans binding enables direct cytoneme-cytoneme contact formation

(A) Wing imaginal discs from $3^{\text {rd }}$ instar larvae carrying flip-out clones expressing UAS-Ihog were immunostained with antibodies against Ihog (green), Ptc (blue), and GFP (red) as indicated. Yellow arrows indicate lhog-enriched cytonemes projecting from closely positioned clones. Scale bar, $20 \mu \mathrm{m}$. (B-D) Apical, lateral, and basal sections of a wing imaginal disc from $3^{\text {rd }}$ instar larvae carrying clones marked by the CoinFLP-LexGAD/GAL4 system and the GRASP system as indicated. The wing discs were immunostained with antibodies against Ihog (red, both lhog-RFP and Ihog $\Delta$ Fn2-HA expressing cells) and HA (blue, Ihog $\Delta$ Fn2-HA expressing cells) as indicated. GRASP signal is green. Blue outlines indicate clones expressing CD4-spGFP $1-10$ and Ihog $\Delta$ Fn2-HA that are immediately adjacent to clones expressing CD4-spGFP 11 and Ihog-RFP; yellow outlines indicate CD4-spGFP1-10 and UAS- Ihog $\Delta F$ n2-HA clones that are distant from those expressing CD4-spGFP 11 and lhog-RFP. Blue arrowheads indicate GFP fluorescence along the apical and lateral sides of the outlined clones. Yellow arrowheads indicate absence of GFP fluorescence along the apical and lateral sides of the outlined clones. (D) Blue and yellow arrows indicate GFP fluorescence along the length of the cytonemes projecting from the clones indicated by blue and yellow outlines $(B, C)$, respectively. Scale bar, $20 \mu \mathrm{m}$. 


\section{Yang_Figure 5}
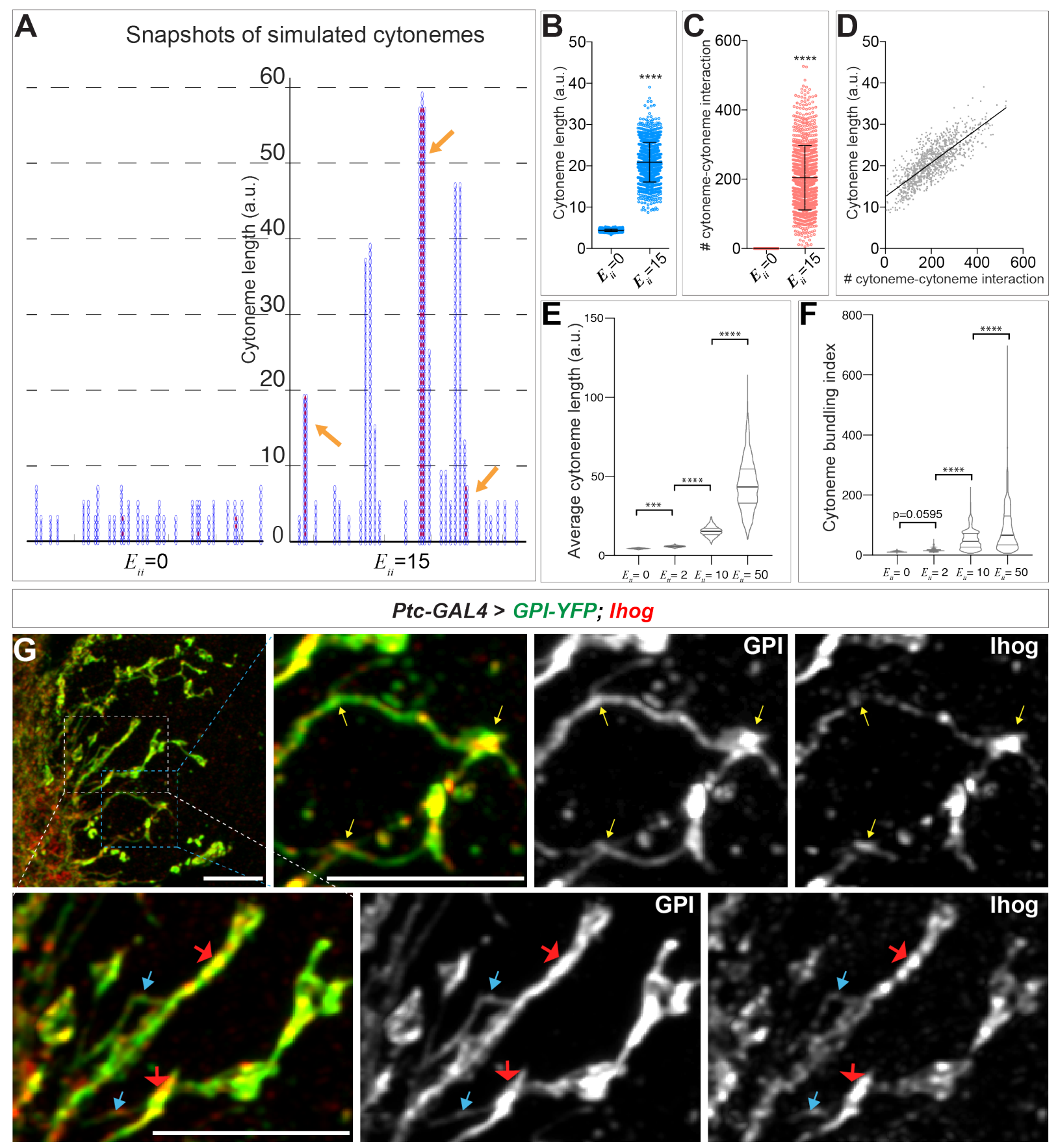
Figure 5. Computational modeling predicts that homophilic trans interactions stabilize cytonemes (A) Snapshots of simulated cytoneme configurations with no (left, $E_{i i}=0$ ) homophilic trans interactions and with moderately strong (right, $E_{i i}=15$ ) homophilic trans interactions. The solid black horizontal lines at the bottom represent the cell surface. The blue vertical filaments are cytonemes, within which the elliptical elements are the individual segments. The red dots are the established pairwise interactions between neighboring segments. The orange arrows indicate the bundled neighboring cytonemes with extensive pairwise contacts. $(\mathrm{B}, \mathrm{C})$ The average cytoneme length and the number of cytoneme-cytoneme interactions at $E_{i i}=0$ and 15 . Each dot is obtained from 1 randomly picked snapshot from the simulation. Each bar shows the mean $\pm S D, n=1001$. (D) Correlation between the cytoneme length and the number of pairwise interactions at $E_{i i}=15$. Each dot represents the length and the number of interactions for individual cytonemes. The grey line shows the best fit linear regression (Pearson $r=0.7939)$. $(E)$ Effect of homophilic trans-interaction strength on the average cytoneme length. The average length of the simulated cytonemes is plotted against $E_{i i}$ ranging from 0 to 50 . Each bar shows the mean $\pm S D, n=1001$. (F) Effect of homophilic transinteraction strength on the formation of cytoneme bundles. The cytoneme bundling index for all cytoneme bundles identified from $n=1001$ random snapshots, each containing 30 cytonemes, were plotted against $E_{i i}$ ranging from 0 to 50 . Each bar shows the mean $\pm S D, n=1001$. The two-tailed unpaired t-test $(B, C)$ or one-way ANOVA followed by Sidak's multiple comparison test $(E, F)$ was used for statistical analysis. ${ }^{* *} P<0.001$, ${ }^{* * *} P<0.0001$. (G) Wing discs from $3^{\text {rd }}$ instar larvae carrying ptc-GAL4, tub-GAL80 ${ }^{t s}$ and UAS-GPI-YFP; UAS-Ihog-RFP were immunostained for YFP (GPI, green) and lhog (lhog, red), followed by imaging with Airyscan. Yellow arrows indicate cytoneme-cytoneme contacts; blue arrows indicate likely single cytonemes; red arrows indicate bundles containing multiple cytonemes. Scale bar, $5 \mu \mathrm{m}$. 


\section{Yang_Figure 6}

A
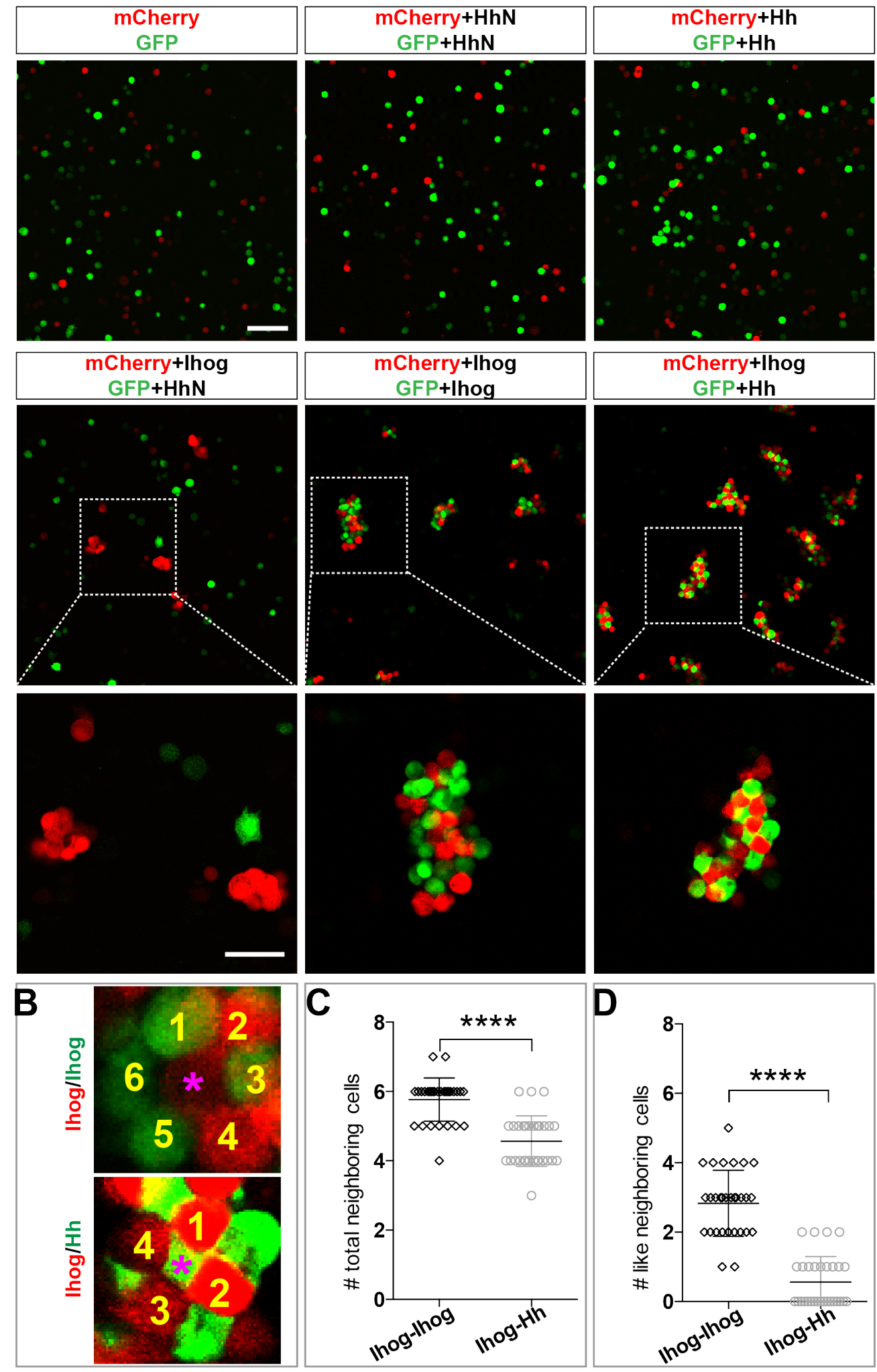


\section{Yang_Figure 6}

Figure 6. Heterophilic binding of Ihog to Hh dominates over lhog-mediated homophilic trans interactions

(A) S2 cells were transfected with plasmids expressing lhog, $\mathrm{Hh}$, or $\mathrm{HhN}$ along with expression plasmids for either GFP or mCherry as indicated. Cells were dissociated by trypsin treatment and then mixed for $12 \mathrm{hr}$ to allow aggregation to occur. The top and middle rows show the mixing of cells expressing only the fluorescent proteins or together with $\mathrm{Hh}, \mathrm{HhN}$ or Ihog. Scale bar, $100 \mu \mathrm{m}$. The bottom row shows the indicated zoomed area from the middle row images. Scale bar, $50 \mu \mathrm{m}$. (B) Representative examples used for quantification of cell patterns in aggregates. The center cells in cell aggregates are indicated by purple asterisks. The neighboring cells are counted and labeled with yellow numbers. (C, D) The average numbers of total neighbor cells and "like" (expressing the same proteins and thus the same color as the center cell) neighbor cells were quantified. Each bar shows the mean $\pm S D, n=30$ cells (from $\mathrm{n}>3$ experiments). The unpaired two-tailed t-test was used for statistical analysis. ${ }^{* * * *} \mathrm{P}<$ 0.0001. 


\section{Yang_Figure 7}

A

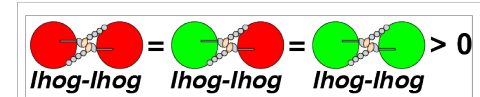

I I homogeneous aggregation

D

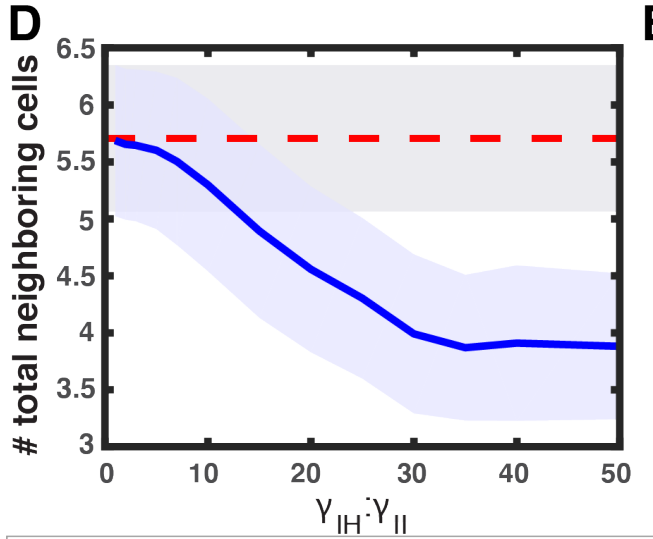

B

(3) $>$ of $>>$ of $=0$ Hh-lhog Ihog-Ihog Hh - Hh

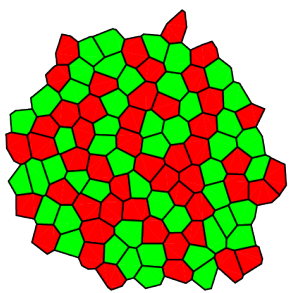

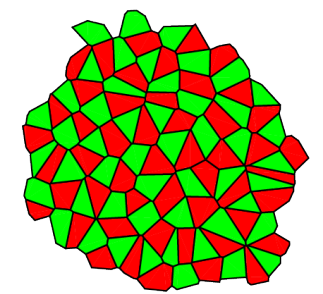

I H heterogeneous aggregation

C
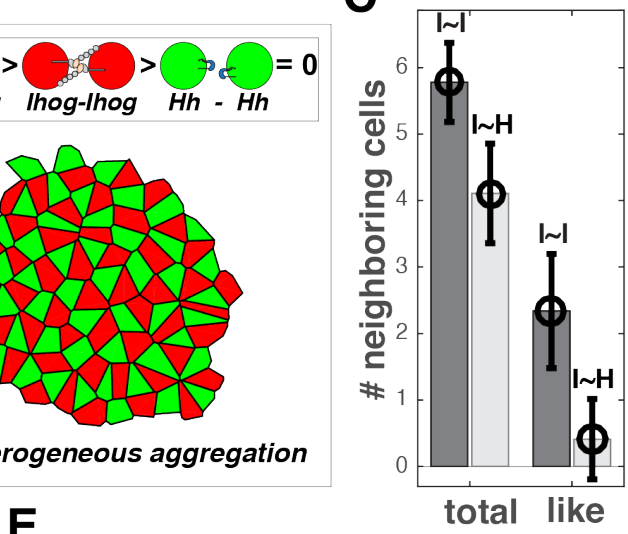

$\mathbf{F}$

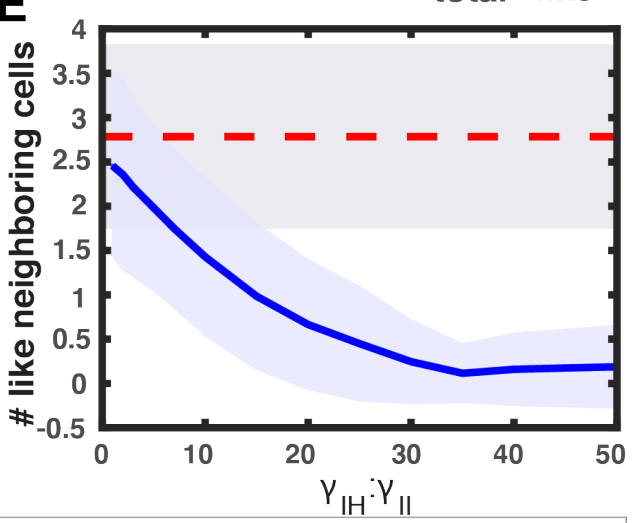

Hh-Ihog Ihog-lhog $\mathrm{Hh}-\mathrm{Hh}=0$

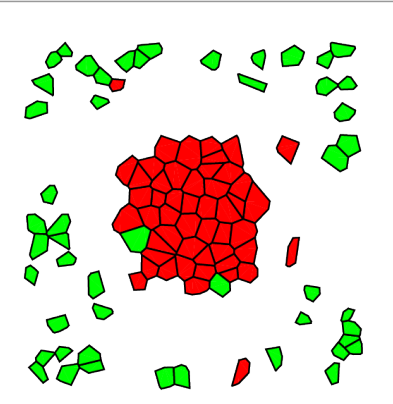

G

GFP+Hh / mCherry+lhog
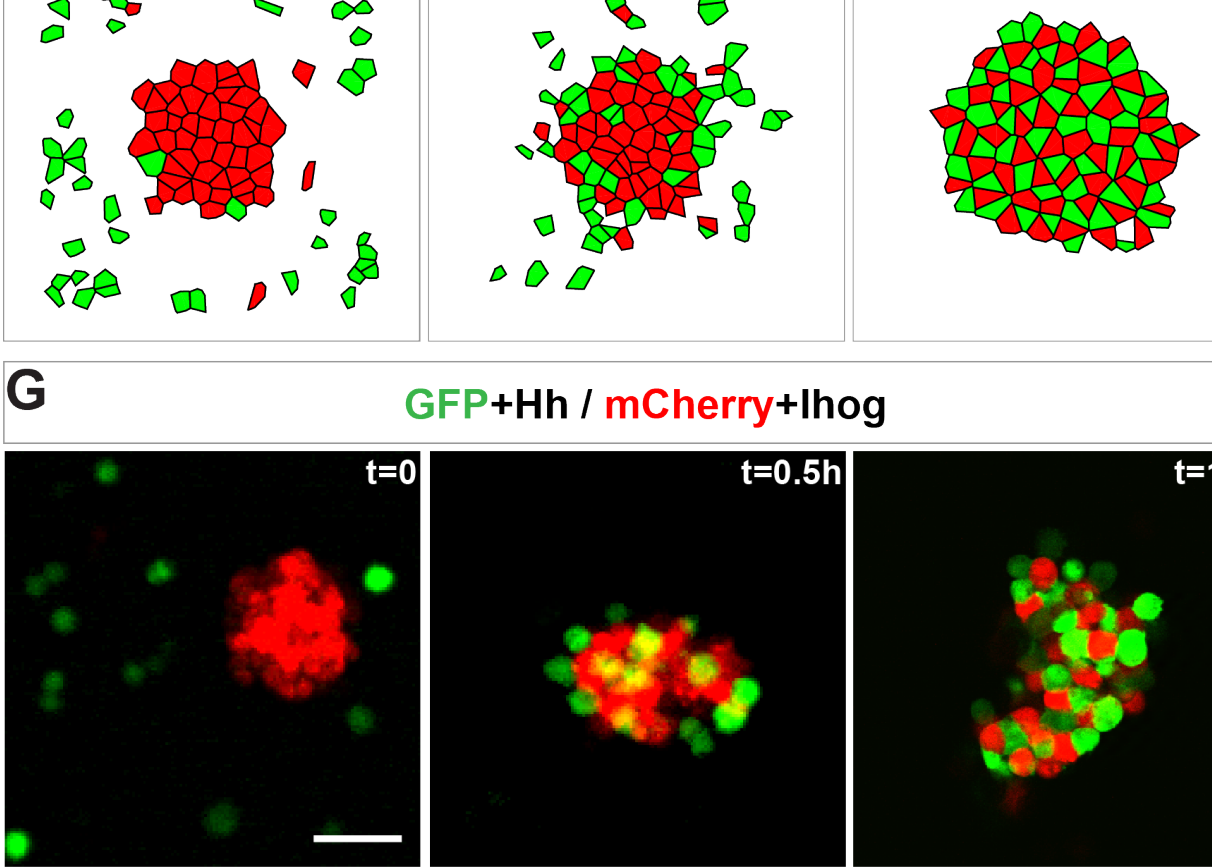

$\Delta 0 \Delta$
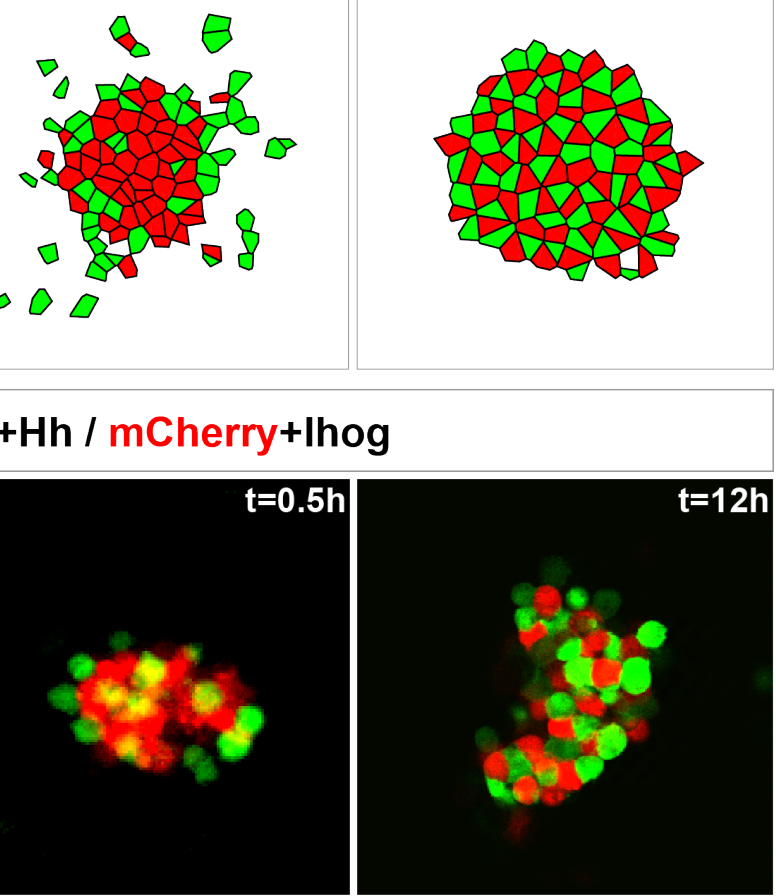


\section{Yang_Figure 7}

Figure 7. In silico simulation estimates the difference in strength between the heterophilic Ihog-Hh and homophilic Ihog-Ihog trans interactions

(A, B) Representative steady-state patterns of the multicellular system from simulations with differentially labeled lhog-expressing cells (A) and mixed lhog- and Hh-expressing cells (B). (C) The average numbers of total neighbor cells and "like" neighbor cells were quantified for scenarios ( $\mathrm{A}, \mathrm{I} \mid \mathrm{I}$ bars) and (B, I H bars). Data were obtained from 300 random snapshots. Each error bar shows the mean $\pm S D$. $(D, E)$ Blue lines are the quantified relationships between the average numbers of total neighbor cells (D) and "like" neighbor cells (E) in a mixed system as a function of the difference in strength between the heterophilic Ihog- $\mathrm{Hh}\left(\gamma_{I H}\right)$ and homophilic Ihog-Ihog $\left(\gamma_{I I}\right)$ trans interactions. For comparison, the red dashed lines mark the values obtained from homogeneous system with differentially labeled lhog-expressing cells. The shaded areas outline the standard deviations around the corresponding central average values. Each data point was calculated using 300 random snapshots from the simulation. (F) Simulation with $\gamma_{I H}: \gamma_{I I}=30$, starting with an aggregate formed from 50 lhog-expressing cells, then $50 \mathrm{Hh}$ expressing cells were added into the simulation space (left). The energy-based evolution leads to the surface engagement of Hh-expressing cells onto the lhog-expressing cell aggregate (middle) and eventually a checkerboard-like morphological pattern (right) appears as the simulation reaches steady state. (G) S2 cells were transfected with plasmids expressing Hh and GFP or Ihog and mCherry as indicated. 48 hours after transfection, cells were resuspended by pipetting and then mixed as indicated. Cell mixture was incubated with gentle rotating for 12 hours. At the indicated time points, an aliquot of cells was removed and imaged with a confocal microscope. Representative images from 3 experiments are shown. Scale bar, $100 \mu \mathrm{m}$. 


\section{Yang_Figure 8}

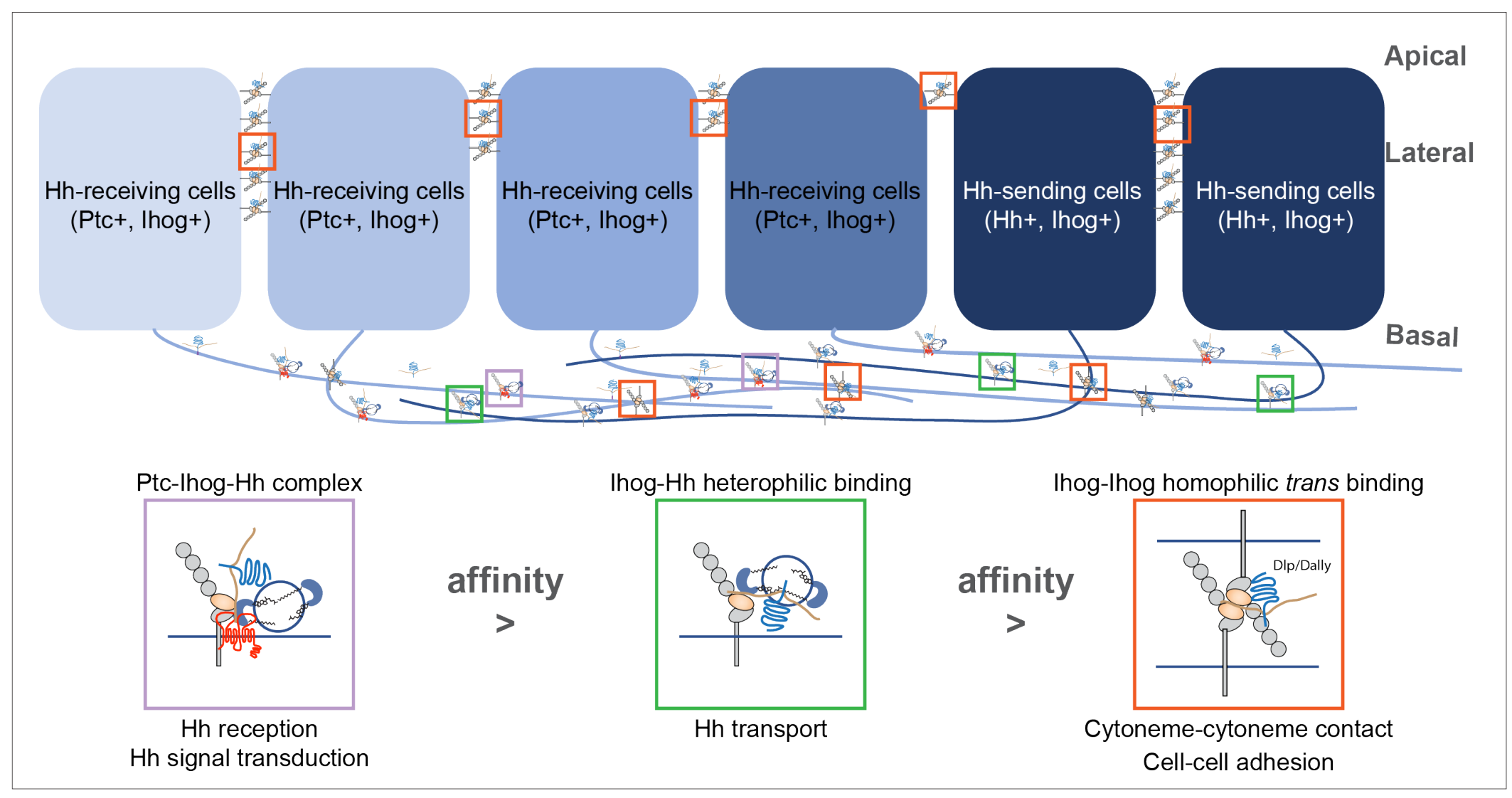




\section{Yang_Figure 8}

Figure 8. A model of the competitive coordination of the dual roles of lhog in homophilic adhesion and signal reception

Diagram illustrating Ihog-Ihog homophilic trans interaction and Ihog-Hh heterophilic interaction in the wing imaginal disc epithelium. For simplicity, only a small number of the apical and lateral interactions are shown. Based on the differential affinity (Ptc-lhog-Hh > Ihog-Hh > Ihog-lhog) and the competitive binding between Ihog for itself (in trans) and for Hh, we propose a model in which Ihog-lhog trans interactions promote and stabilize cytoneme-cytoneme contacts, thereby facilitating the "capture" of Hh ligands released by cytonemes of Hh-expressing cells by Ihog on cytonemes of adjacent cells, ultimately reaching lhog on cytonemes of Hh-receiving cells. The stronger Hh-lhog interaction triggers release of lhog from the weaker trans-homophilic interaction, enabling the receptorligand complex to transport along the cytoneme. Ultimately, the strongest interaction of $\mathrm{Hh}$ with the Ptc and Ihog complex results in $\mathrm{Hh}$ signal transduction. Both $\mathrm{Hh}$ release and cytoneme formation occur at the basal side of the wing disc epithelium, making weaker Ihog-Ihog trans interactions accessible for the replacement by stronger Ihog-Hh interactions along the cytonemes, where Ihog also functions as the receptor for $\mathrm{Hh}$ transport and reception. In contrast, farther from the source of secreted Hh, heterophilic Ihog-Hh interactions would be infrequent along the lateral side of epithelia, where the trans lhog-lhog interaction plays an essential role in maintaining A/P cell segregation and lineage restriction. The heparan sulfate necessary for the Ihog-Hh or trans Ihog-lhog interactions may be supplied by Dally or Dlp, either as the membrane-associated forms of these glypicans or as the form released upon shedding. 


\section{Yang_Supplementary Figure 1}

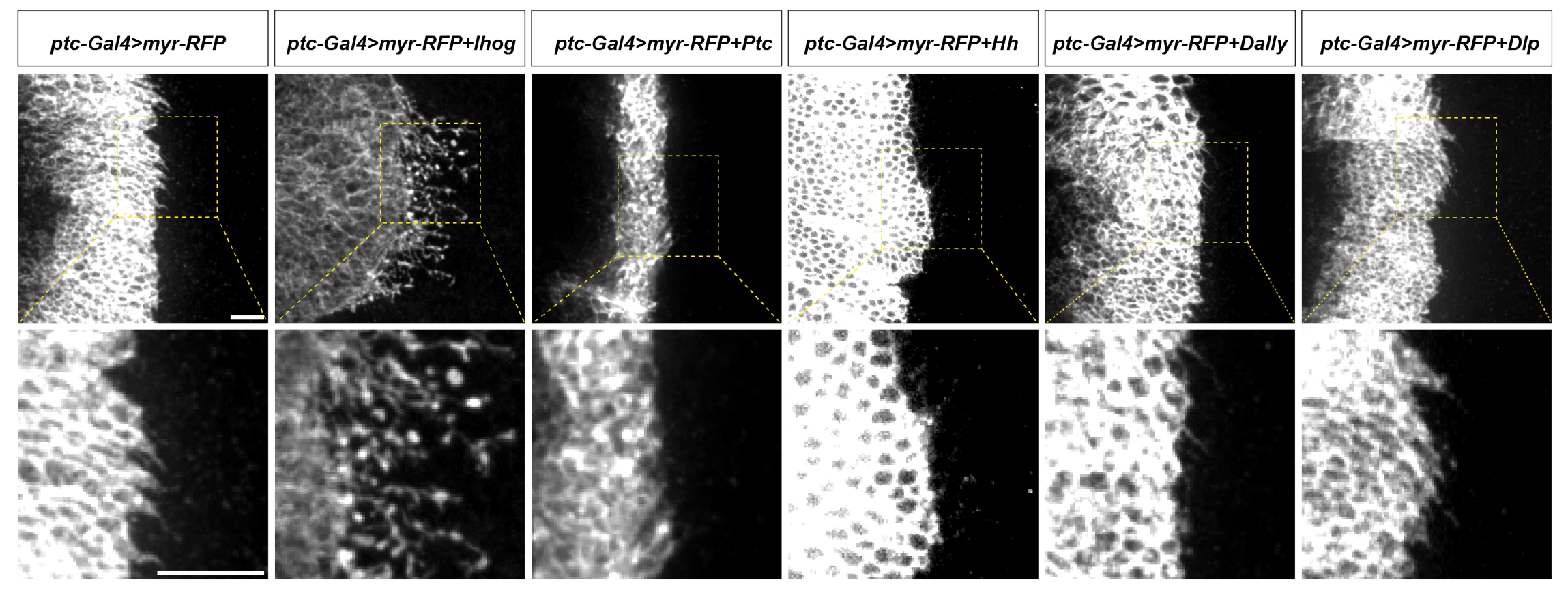

Supplementary Figure 1. Ectopic expression of Ihog, but not other Hh pathway components, stabilizes cytonemes

Wing discs from $3^{\text {rd }}$ instar larvae carrying ptc-GAL4, tub-GAL8O ${ }^{\text {ts }}$ and the indicated UAS-transgenes were immunostained for RFP to visualize cytonemes projecting from Hh-receiving cells. UAS-Myr-RFP: myristoylated form of red fluorescent protein that marks the cell membrane and enables visualization of the cytonemes. Scale bar, $10 \mu \mathrm{m}$. 


\section{Yang_Supplementary Figure 2}
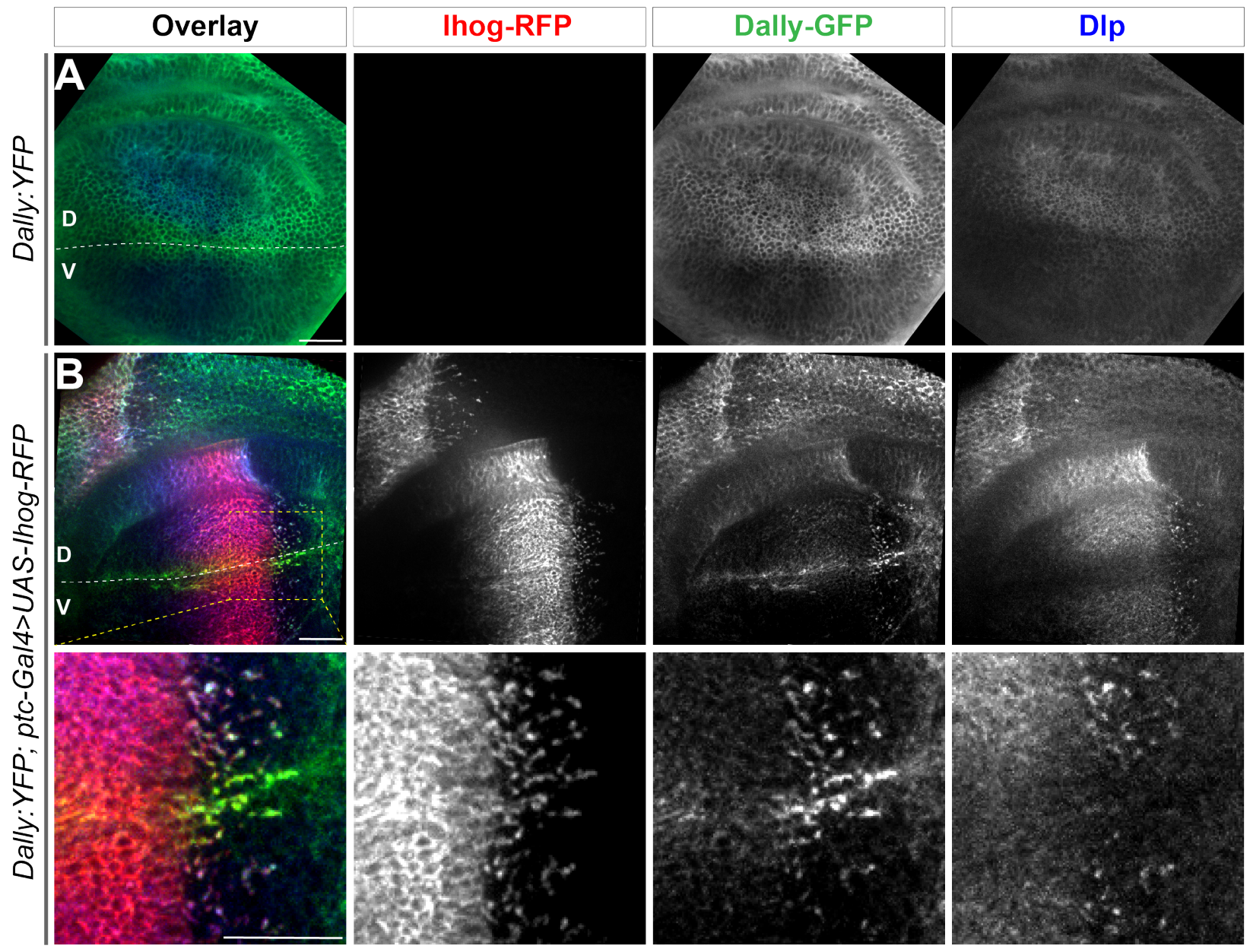

Supplementary Figure 2. Ectopic lhog induces accumulation of Dally and DIp that is associated with the different distributions of the two glypicans

((A) Distribution of Dally:YFP and DIp in a wing discs from a $3^{\text {rd }}$ instar larvae carrying a

Dally:YFP protein trap allele. (B) Distribution of Dally:YFP, Dlp, and lhog in a wing disc from larvae expressing the a Dally:YFP protein trap allele and the ptc-GAL4, tub-GAL80 ${ }^{t s}$ and UASIhog-RFP transgenes. The lower row shows an enlarged area (outlined in upper left panel) around the D/V boundary. The discs were immunostained to visualize Dlp (blue) and with antibody against YFP to visualize Dally (green). Ihog-RFP was visualized with the RFP fluorescence (red). The dorsal/ventral (D/V) boundary is indicated by a dashed white line. Scale bar, $20 \mu \mathrm{m}$. 


\section{Yang_Supplementary Figure 3}

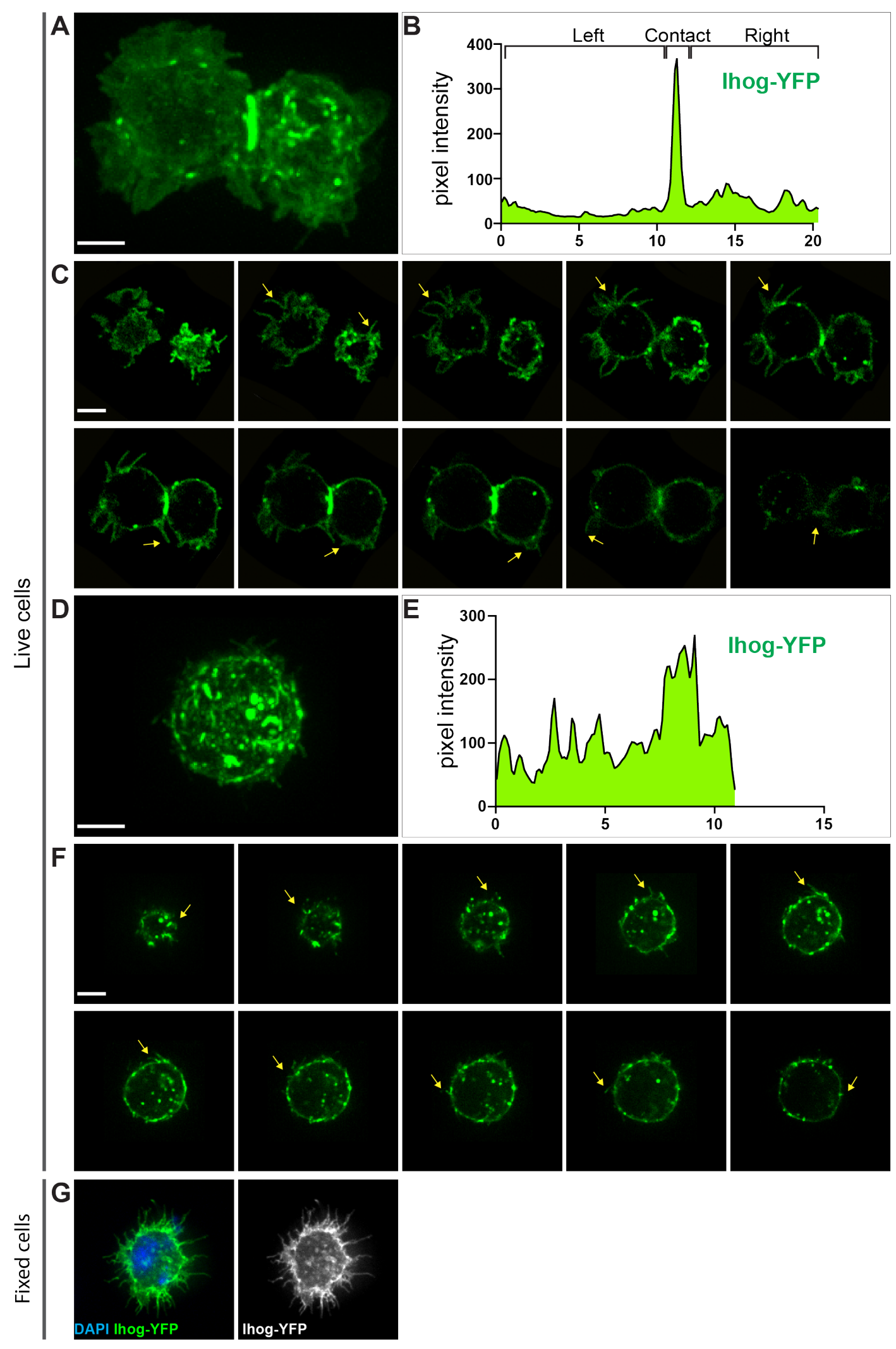




\section{Yang_Supplementary Figure 3}

\section{Supplementary Figure 3. Subcellular localization of Ihog proteins in live S2 cells}

(A-F) Live imaging of S2 cells transfected with plasmids expressing YFP-tagged lhog was performed and pixel intensity plotted. Images of $x y$ focal planes were collected along the $z$-axis through the $\mathrm{S} 2$ cells with each image consisting of a maximum projection of three-dimensional volume encompassing the entire cell(s). (A, B) Representative maximum intensity projections of z-stack sections of S2 cells in contact and pixel intensity of Ihog-YFP across the image. Data are representative of $n>3$ experiments. (C) Images from 10 different $x y$ focal planes with identical z-axis distance for the cells shown in C. Arrows indicate filopodia. See Supplementary Movies 1, 2. (D, E) Representative maximum intensity projections of z-stack sections of single S2 cells and pixel intensity of Ihog-YFP across the image. Data are representative of $n>3$ experiments. (F) Images from 10 different $x y$ focal planes with identical z-axis distance for the cell shown in D. See Supplementary Movies 3, 4. (G) S2 cells transfected with plasmids expressing Ihog-YFP were plated on the glass surface, and stained for YFP following MEM-fix as previously described (73). Scale bar, $5 \mu \mathrm{m}$. 


\section{Yang_Supplementary Figure 4}
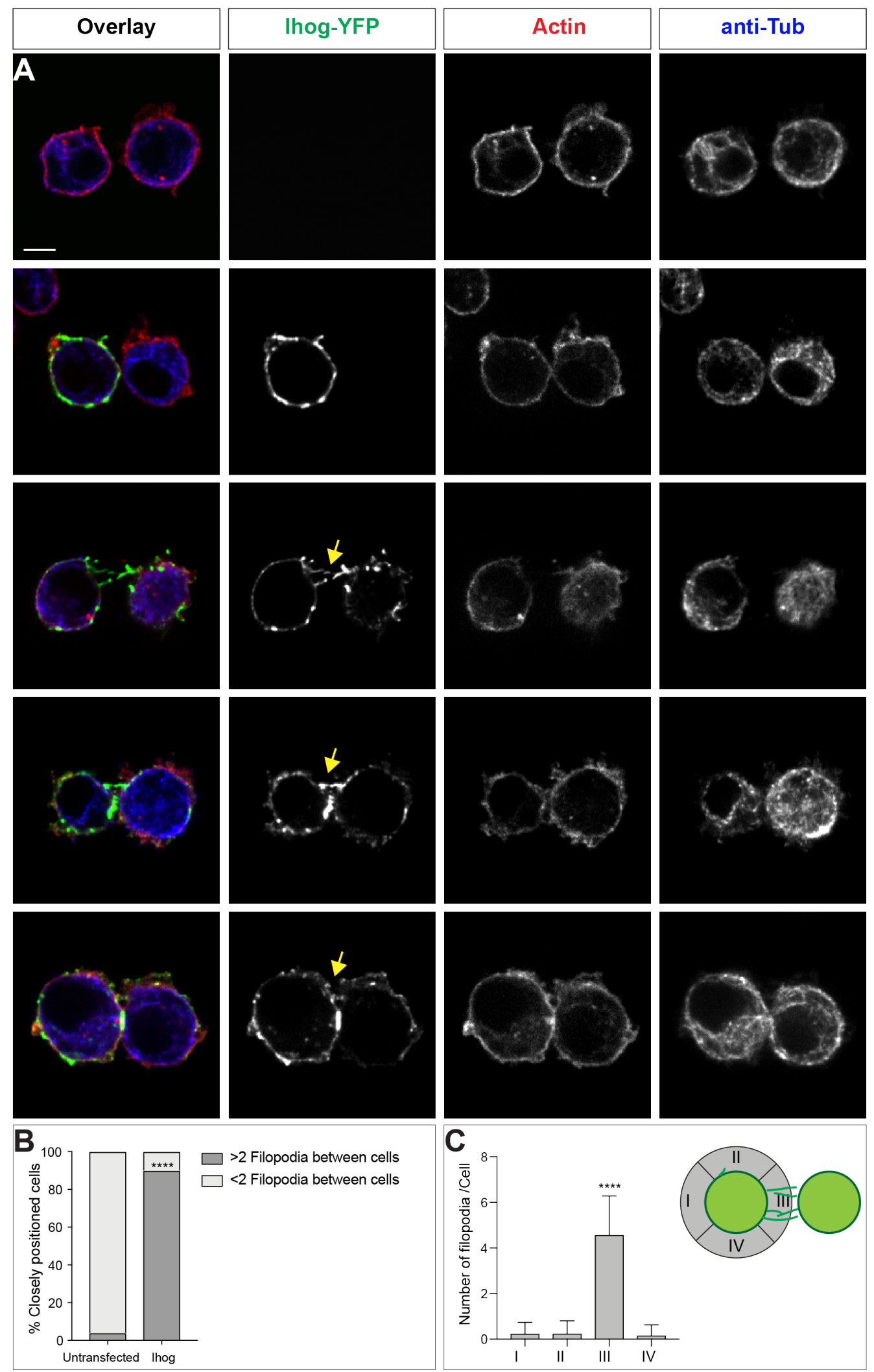


\section{Yang_Supplementary Figure 4}

\section{Supplementary Figure 4. Ihog is enriched in filopodia-like structures of closely positioned lhog-expressing cells.}

S2 cells transfected with plasmids expressing lhog-YFP were plated on the glass surface, fixed, and stained for actin (Phalloidin, red) and alpha-tubulin (blue). Representative images of two closely positioned untransfected cells $(A)$, singular lhog-expressing cell located next to an untransfected cell, two closely positioned lhog-expressing cells (C-D), and lhog-expressing cells that appear to start forming a stable contact (E). Scale bar, $5 \mu \mathrm{m}$. (F) Quantification of the presence and absence of filopodia between closely located S2 cells with or without Ihog expression. Two-sided Fisher's exact test was used for statistical analysis. ${ }^{* * *} P<0.0001$. (G) Quantification of filopodia spatial distribution of lhog-expressing cells closely located to another Ihog-expressing cell. one-way ANOVA followed by Tukey's multiple comparison test was used for statistical analysis. ${ }^{* * * *} \mathrm{P}<0.0001$. 


\section{Yang_Supplementary Figure 5}
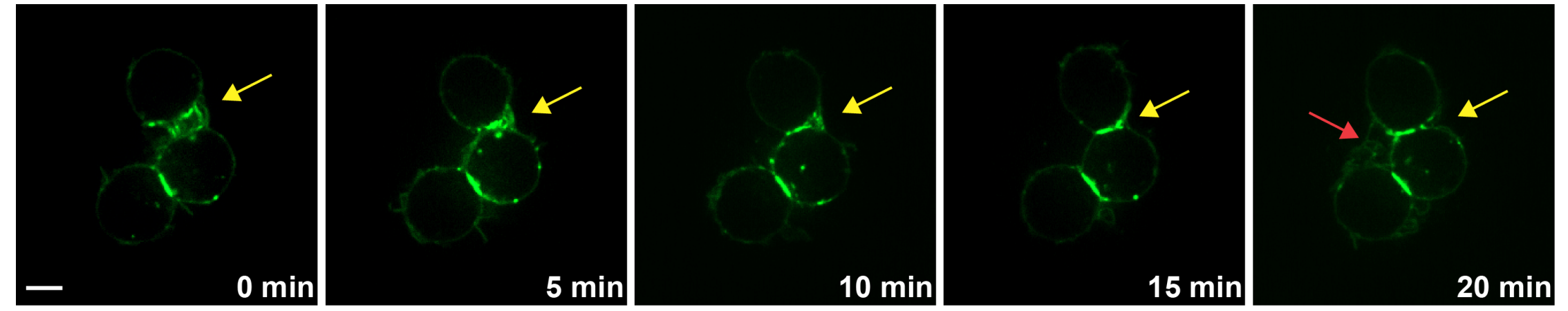

Supplementary Figure 5. Live imaging shows that cell-cell contact occurs at sites of interaction between Ihog-enriched filopodia.

Time-lapse imaging of S2 cells expressing Ihog-YFP. Interdigitation of filopodia at the region where lhog-expressing cells initiate contact formation (yellow arrow). Progressively, filopodia are replaced by stable extensive contact between opposing cell membranes. Red arrow indicates a new cell-cell contact initiated by Ihog-YFP-positive filopodia. Scale bar, $5 \mu \mathrm{m}$. 


\section{Yang_Supplementary Figure 6}
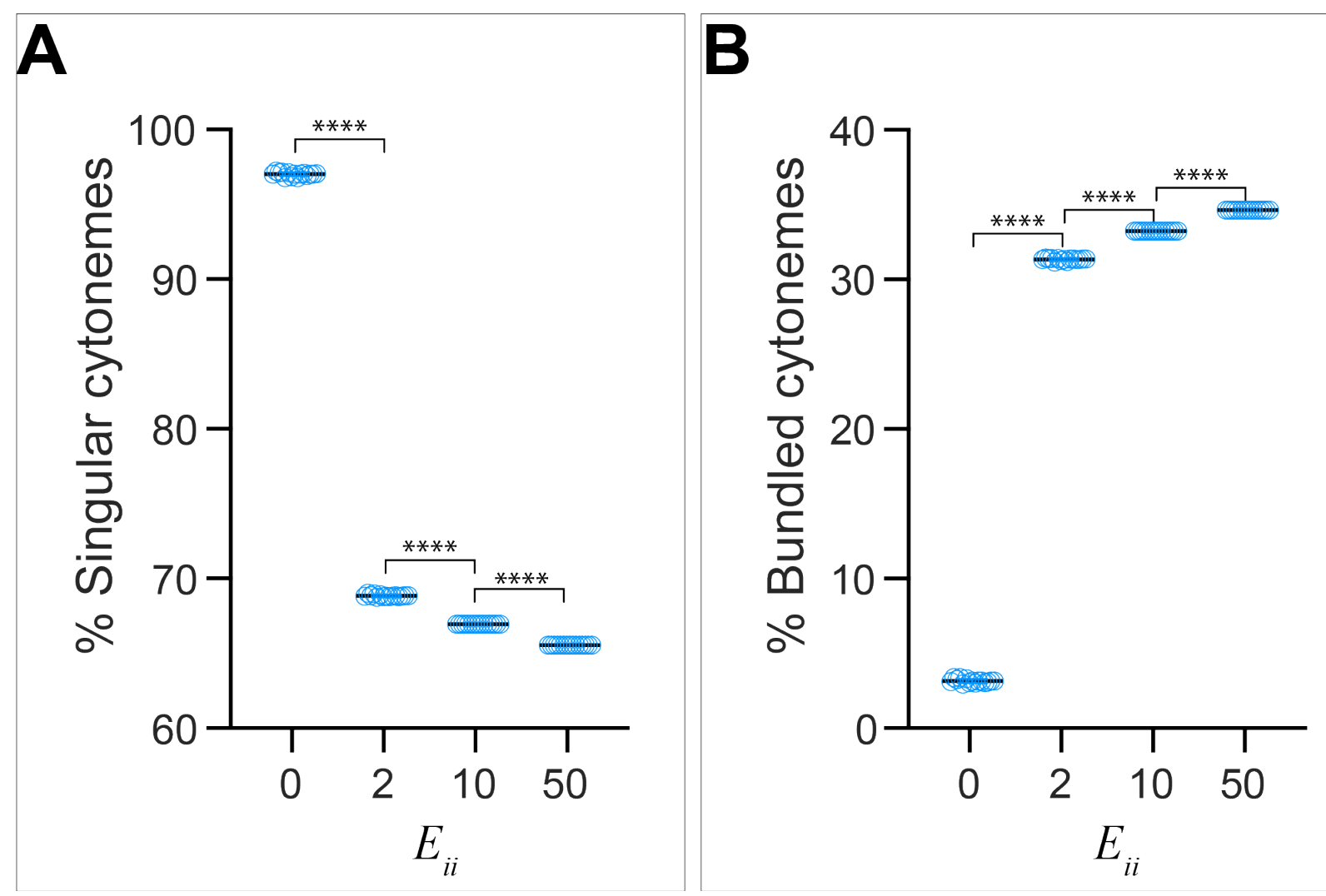

Supplementary Figure 6. Effect of homophilic trans-interaction strength on the frequency of cytoneme bundle formation.

The ratio of singular cytonemes $(A)$ and the ratio of cytonemes present in bundles $(B)$ from $\mathrm{n}=1001$ random snapshots, each containing 30 cytonemes, are plotted against $E_{i i}$ ranging from 0 to 50 . Each bar shows the mean \pm SD, one-way ANOVA followed by Sidak's multiple comparison test was used for statistical analysis. ${ }^{* * *} \mathrm{P}<0.0001$. 


\section{Yang_Supplementary Figure 7}
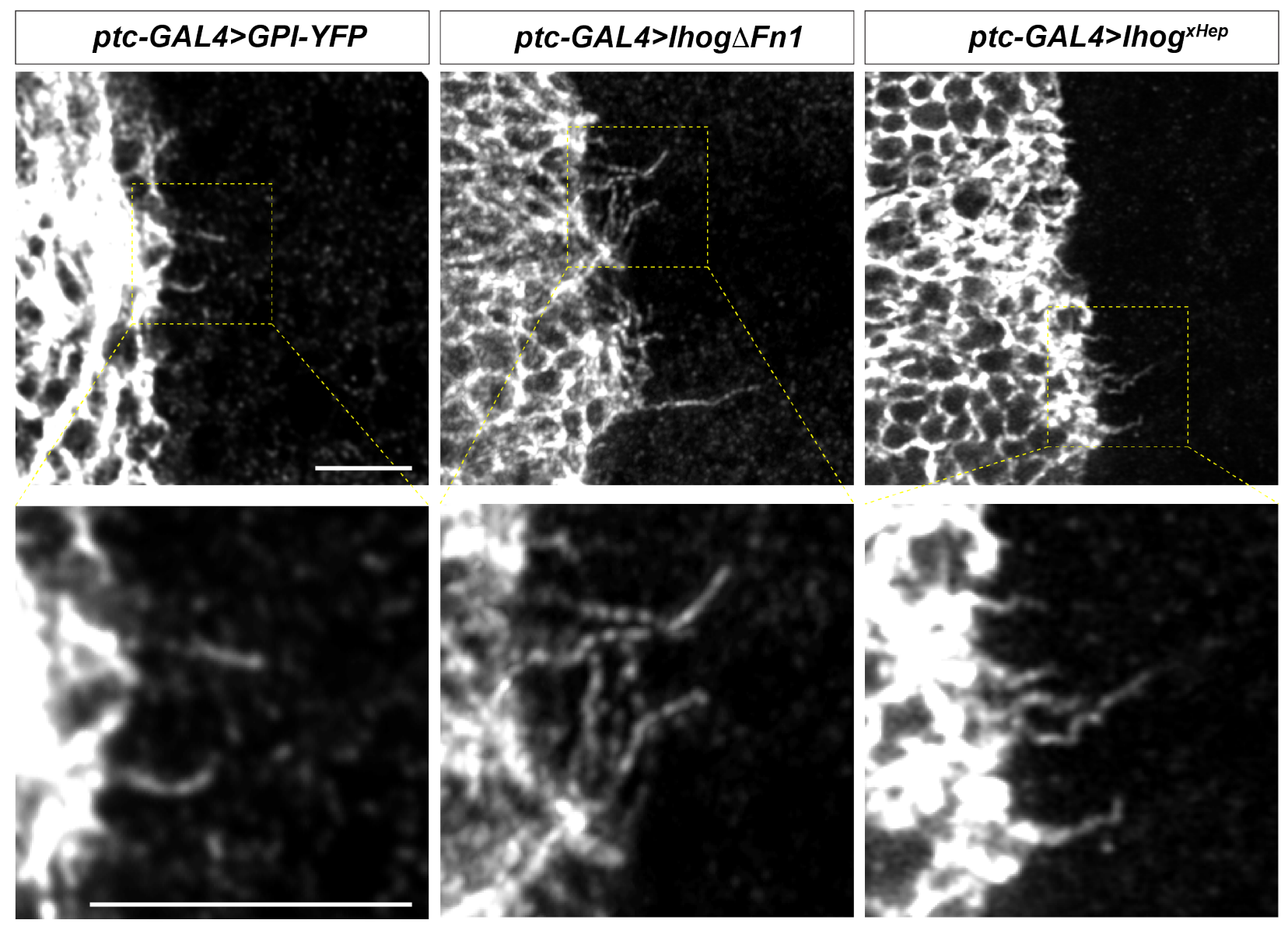

Supplementary Figure 7. The Ihog Fn1 domain is essential for cytoneme bundling.

Wing discs from $3^{\text {rd }}$ instar larvae carrying ptc-GAL4, tub-GAL80 ${ }^{\text {ts }}$ and the indicated UAS-

transgene were immunostained and imaged with Airyscan. Scale bar, $5 \mu \mathrm{m}$. 


\section{Yang_Supplementary Figure 8}

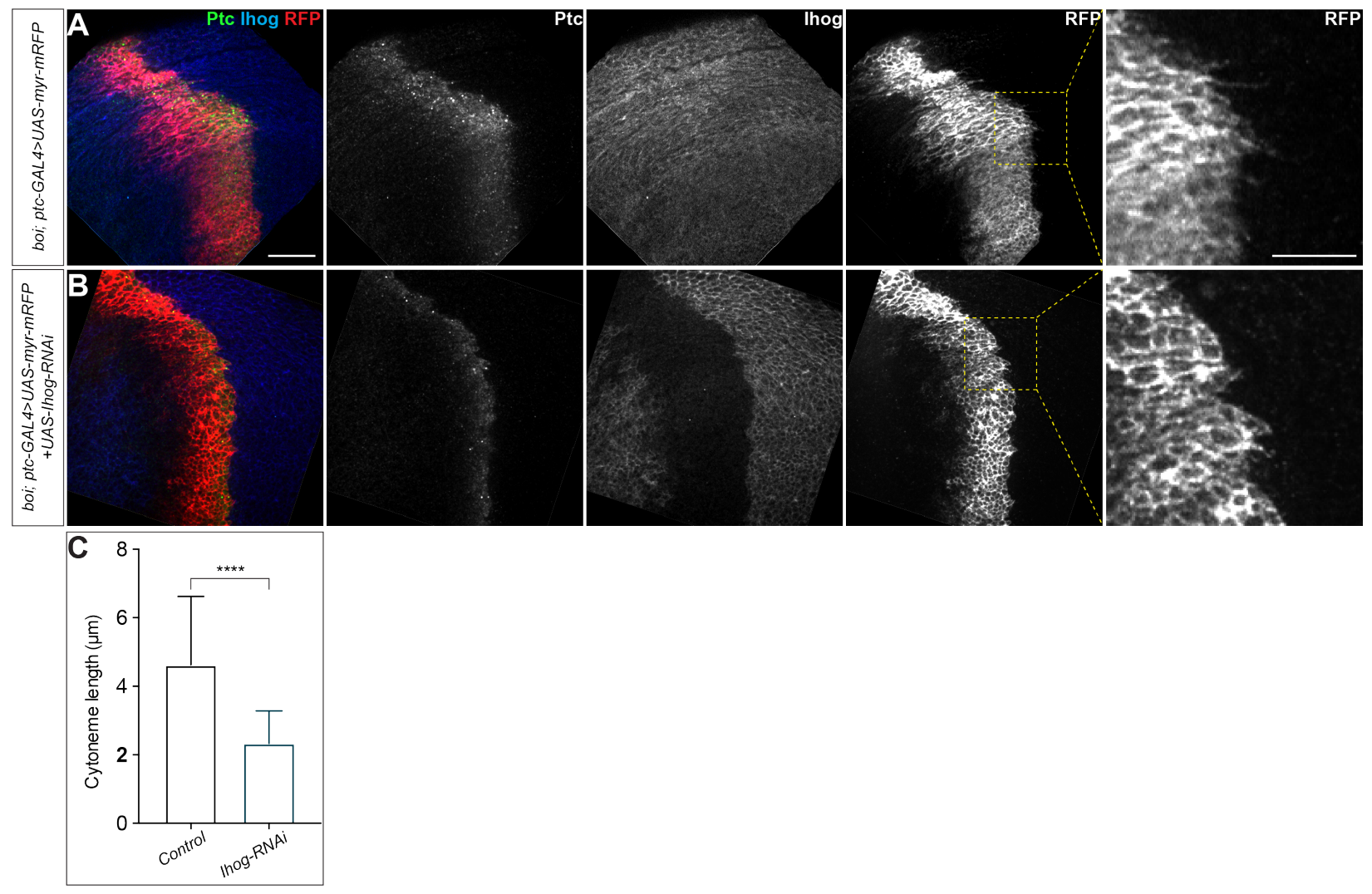

Supplementary Figure 8. Loss of $/$ hog and its close paralogue boi from the wing imaginal discs cells resulted in cytonemes with reduced length.

(A, B) Wing discs from $3^{\text {rd }}$ instar boi mutant larvae carrying the ptc-GAL4, tub-GAL8O ${ }^{\text {ts }}$ and the indicated UAS transgenes were immunostained to visualize Ptc (anti-Ptc, green), Ihog (antiIhog, blue), and the cytonemes (anti-RFP, red). Note that expression of UAS-Ihog-RNAi lead to loss of Ihog expression in the Ptc expressing domain (B) and resulted in cytonemes with reduced length. Scale bar, $20 \mu \mathrm{m}$. (C) Quantification of the average cytoneme length. Each bar shows the mean $\pm S D, n=30$, and representative images are shown in (A, B). Two-tailed unpaired t-test was used for statistical analysis. ${ }^{* * *} \mathrm{P}<0.0001$. 


\section{Yang_Supplementary Figure 9}
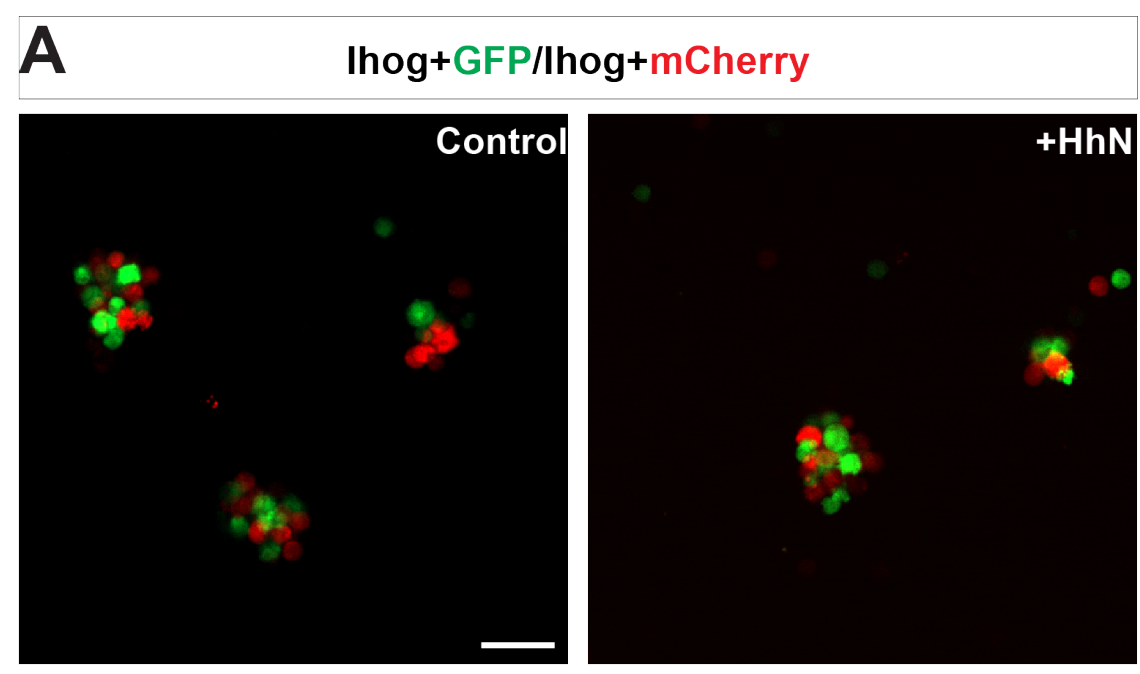

B

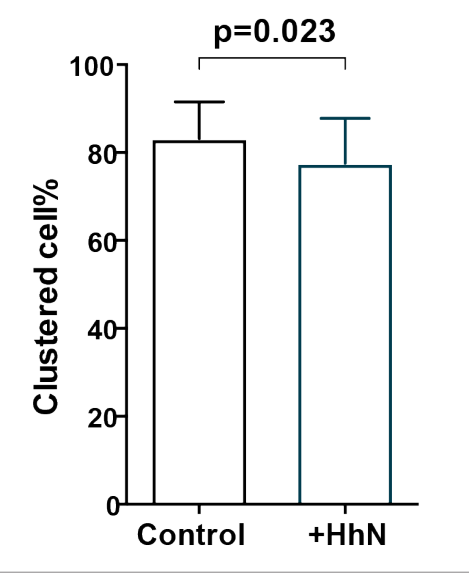

Supplementary Figure 9. Ihog-mediated homophilic trans interaction in $\mathbf{S 2}$ cells occurs in the presence of recombinant $\mathrm{HhN}$.

(A) S2 cells were transfected with plasmids expressing wild-type lhog along with GFP or mCherry. Cells were dissociated by trypsin treatment and then mixed in the absence or presence of $\mathrm{HhN}(30 \mu \mathrm{M})$ for $4 \mathrm{hr}$. Scale bar, $50 \mu \mathrm{m}$. (B) The aggregation effect from experiments like those shown in (A) was quantified as the ratio of transfected cells within a cluster to total transfected cells. Each bar shows the mean \pm SD from $n=30$ different images. The unpaired two-tailed t-test was used for statistical analysis. 


\section{Yang_Supplementary Figure 10}
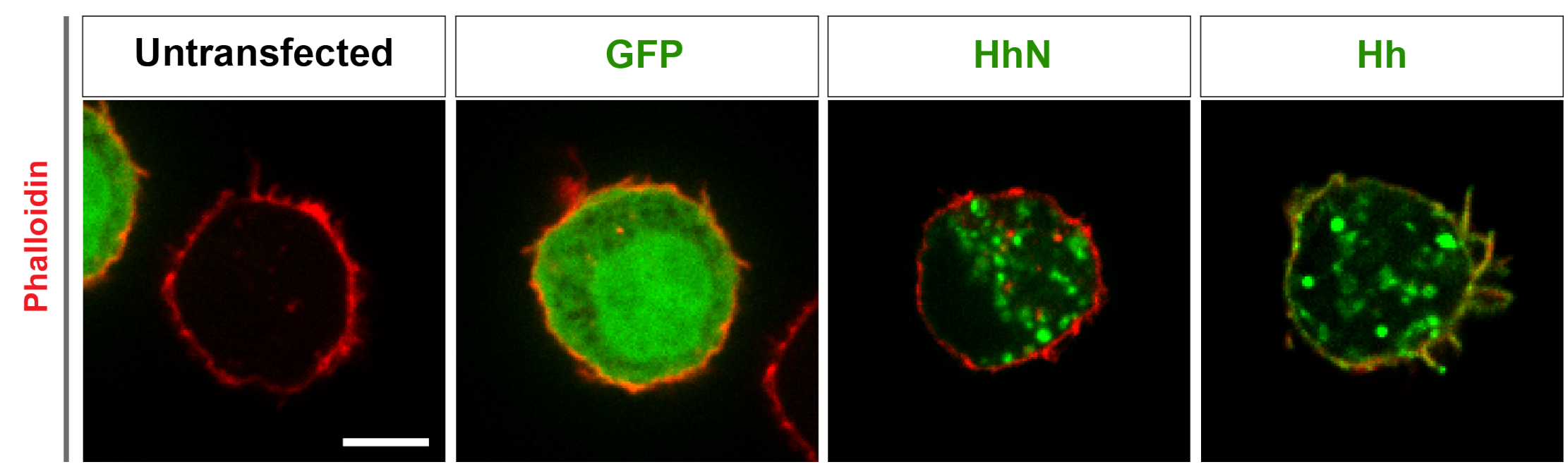

Supplementary Figure 10. Subcellular localization of Hh and HhN in S2 cells.

Untransfected S2 cell or S2 cells were transfected with constructs expressing GFP, cDNA encoding full-length Hh to generate Hh proteins that are fully processed and dual lipid modified, or cDNA encoding the amino-terminal signaling fragment $\mathrm{HhN}$ to generate cholesterol-free HhN. 48 hours after transfection, the S2 cells were fixed and stained with Phalloidin to detect actin (red) and the antibodies against the indicated proteins (green). Phalloidin stains filopodia-like structures and the submembrane actin network. Note that the untransfected cell is from the control cells transfected with only GFP and is from the same experiment and image. The GFP cell is partially visible in the untransfected cell image (left corner) and the nontransfected cell is partially visible in the lower right of the GFP cell image. Scale bar, $5 \mu \mathrm{m}$. 


\section{Yang_Supplementary Figure 11}

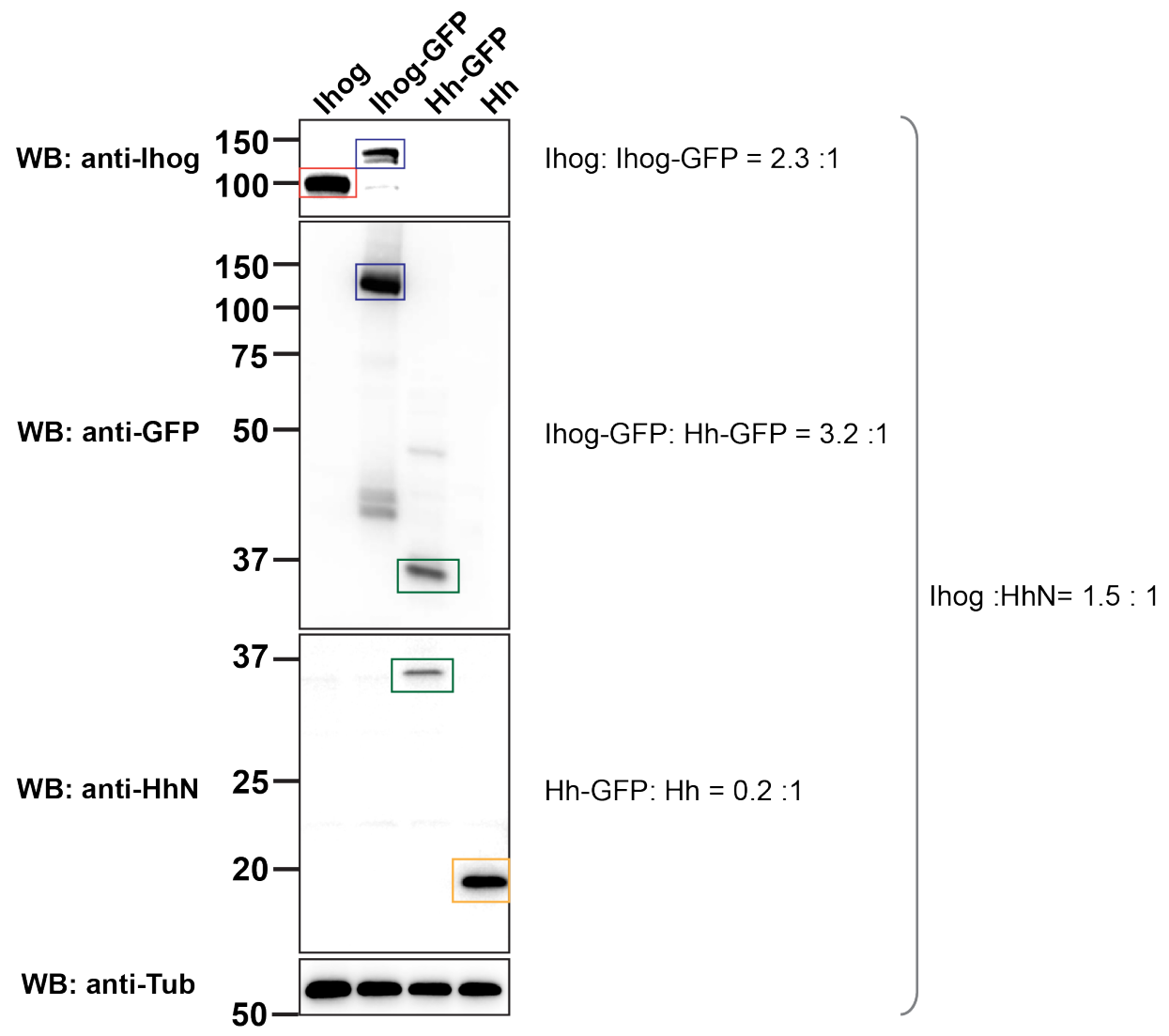

Supplementary Figure 11. Comparison of the amount of Ihog and Hh in S2 cells analyzed in the cell-mixing assay.

Aliquots of the same S2 cells analyzed in the cell mixing assay in Fig. 6 were lysed before cell mixing (Lane 1 and Lane 4). To indirectly compare the relative amounts of Ihog and Hh, lysates were collected from S2 cells that were transfected in parallel with plasmids expressing IhogGFP or Hh-GFP (Lane 2 and Lane 3). The amount of Ihog (red rectangle) or Hh (orange rectangle) was detected by immunoblotting with anti-lhog or anti-Hh, respectively. The amount of GFP-tagged Ihog (blue rectangles) or GFP-tagged Hh (green rectangles) was also detected by anti-GFP. The intensity of the indicated bands was measured by ImageJ. Comparison of the intensity shows that S2 transfected cells from the same experiment used for the aggregation assays express comparable amounts $(\sim 1.5: 1)$ of Ihog and Hh proteins. 


\section{Yang_Supplementary table 1}

\begin{tabular}{|c|c|}
\hline Figure $1 \mathrm{~A}$ & 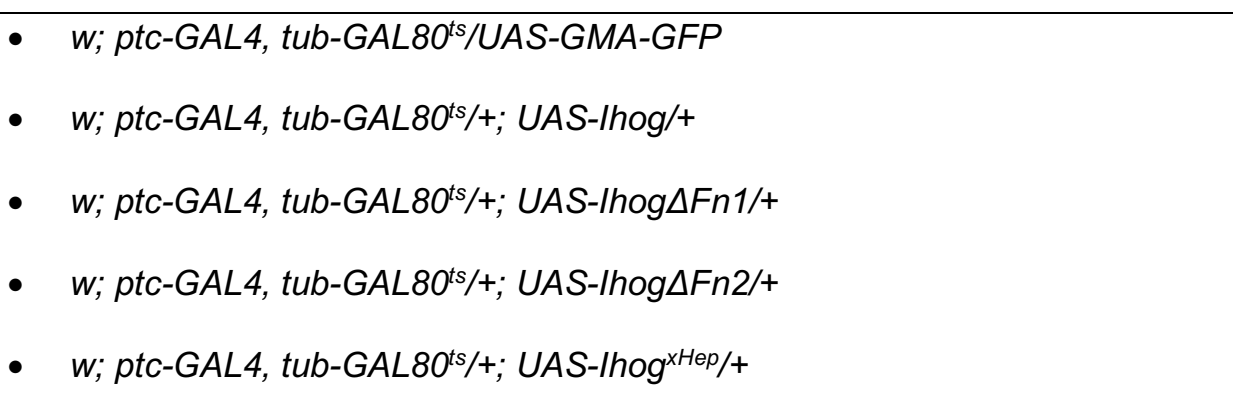 \\
\hline Figure 2 & $\begin{array}{l}\text { (A) w, hs-FLP; } h s-F L P /+; \text { actin>y+>GAL4/+; UAS-Ihog/+ } \\
\text { (C) w, hs-FLP; hs-FLP/+; actin>y+>GAL4/+; UAS-Ihog } \Delta F n 2 /+\end{array}$ \\
\hline Figure $3 \mathrm{~A}$ & $\begin{array}{l}\text { w, hs-FLP; hs-FLP/+; actin>y+>GAL4/+; UAS-Ihog/+ } \\
\text { w, hs-FLP; hs-FLP/+; actin>y+>GAL4/+; UAS-Ihog } / F n 1 /+ \\
\text { w, hs-FLP; hs-FLP/+; actin>y+>GAL4/+; UAS-lhog } \triangle F n 2 /+ \\
w, h s-F L P ; ~ h s-F L P /+; \text { actin>y+>GAL4/+; UAS-lhog }{ }^{x H e p /+}\end{array}$ \\
\hline Figure 3B & w, hs-FLP; hs-FLP/+; actin>y+>GAL4/+; UAS-Ihog/+ \\
\hline Figure 4 & $\begin{array}{l}\text { (A) } w, h s-F L P ; ~ h s-F L P /+; \text { actin>y+>GAL4, UAS-GFP/+; UAS-Ihog/+ } \\
\text { (B-D) w, hs-FLP/+; P\{y[+t7.7] w[+mC]=CoinFLP-LexA::GAD.GAL4\}attP40/UAS- } \\
\text { Ihog } \triangle F n 2-H A ; P\{w[+m C]=U A S-C D 4-s p G F P 1-10\} 3, P\{w[+m C]=l e x A o p-C D 4- \\
\text { spGFP11\}3/LexAop-Ihog-RFP }\end{array}$ \\
\hline Figure 5 & (G) w; ptc-GAL4, tub-GAL80ts/+; UAS-Ihog/UAS-GPI-YFP \\
\hline $\begin{array}{l}\text { Supplementary } \\
\text { Figure } 1\end{array}$ & 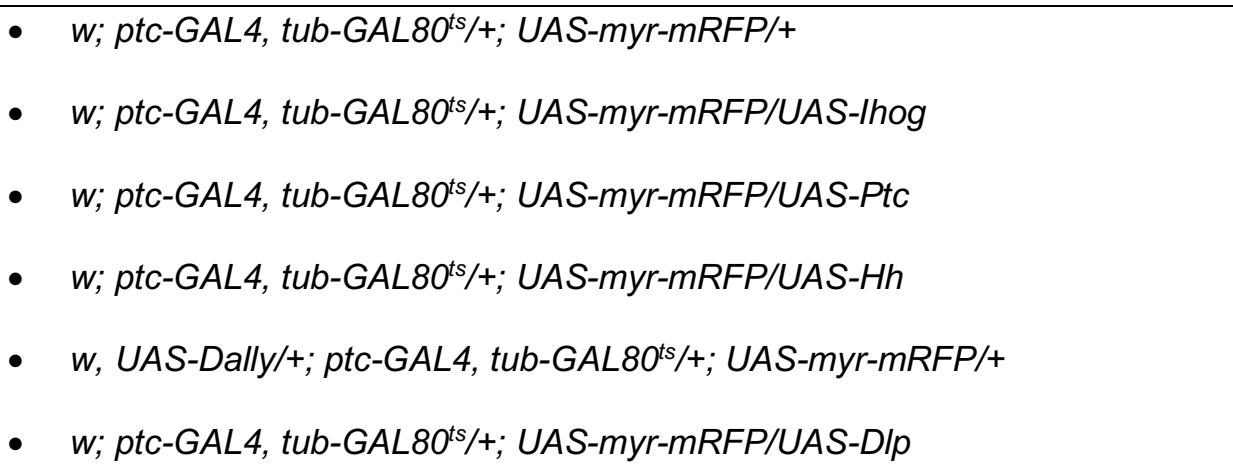 \\
\hline $\begin{array}{l}\text { Supplementary } \\
\text { Figure } 2\end{array}$ & $\begin{array}{l}\text { (A) w; ptc-GAL4, tub-GAL80 }{ }^{t s} /+; \text { Dally-YFP/+ } \\
\text { (B) w; ptc-GAL4, tub-GAL80 } 80^{t s} /+; D a l l y-Y F P / U A S-l h o g-R F P\end{array}$ \\
\hline
\end{tabular}




\begin{tabular}{|c|c|}
\hline $\begin{array}{l}\text { Supplementary } \\
\text { Figure } 7\end{array}$ & 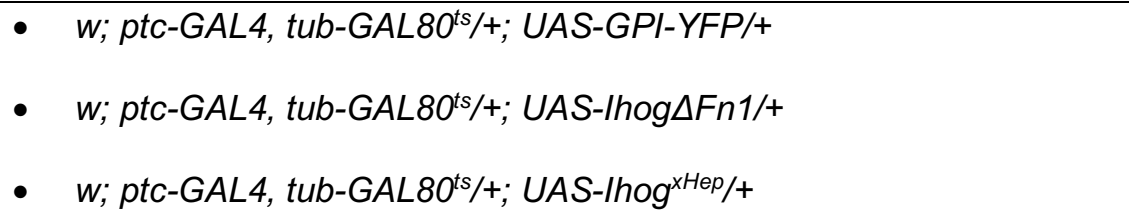 \\
\hline $\begin{array}{l}\text { Supplementary } \\
\text { Figure } 8\end{array}$ & $\begin{array}{l}\text { (A) w, boi/Y; ptc-GAL4, tub-GAL80's/+; UAS-myr-mRFP/Tm6B } \\
\text { (B) w, boi/Y; ptc-GAL4, tub-GAL80"s/+; UAS-myr-mRFP/UAS-Ihog-RNAi }\end{array}$ \\
\hline
\end{tabular}

Supplementary table 1. Genotype of larvae for generating mosaic clones 